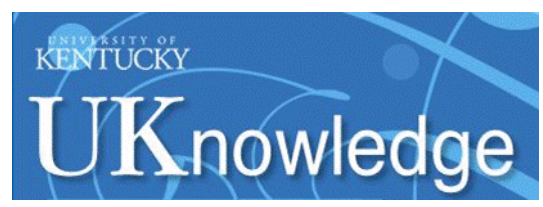

University of Kentucky

UKnowledge

7-1-1995

\title{
The Hubble Space Telescope Sample of Radio-loud Quasars: Ultraviolet Spectra of the First 31 Quasars
}

\author{
Beverley J. Wills \\ University of Texas at Austin \\ Keith L. Thompson \\ University of Texas at Austin \\ Mingsheng Han \\ University of Texas at Austin \\ H. Netzer \\ Tel Aviv University, Israel \\ D. Wills \\ University of Texas at Austin
}

See next page for additional authors

Follow this and additional works at: https://uknowledge.uky.edu/physastron_facpub

Part of the Astrophysics and Astronomy Commons, and the Physics Commons

Right click to open a feedback form in a new tab to let us know how this document benefits you.

\section{Repository Citation}

Wills, Beverley J.; Thompson, Keith L.; Han, Mingsheng; Netzer, H.; Wills, D.; Baldwin, J. A.; Ferland, Gary J.; Browne, I W. A.; and Brotherton, M. S., "The Hubble Space Telescope Sample of Radio-loud Quasars: Ultraviolet Spectra of the First 31 Quasars" (1995). Physics and Astronomy Faculty Publications. 163. https://uknowledge.uky.edu/physastron_facpub/163

This Article is brought to you for free and open access by the Physics and Astronomy at UKnowledge. It has been accepted for inclusion in Physics and Astronomy Faculty Publications by an authorized administrator of UKnowledge. For more information, please contact UKnowledge@lsv.uky.edu. 


\section{The Hubble Space Telescope Sample of Radio-loud Quasars: Ultraviolet Spectra}

of the First 31 Quasars

Digital Object Identifier (DOI)

http://dx.doi.org/10.1086/175861

\section{Notes/Citation Information}

Published in The Astrophysical Journal, v. 447, no. 1, p. 139-158.

(C) 1995. The American Astronomical Society. All rights reserved.

The copyright holder has granted permission for posting the article here.

Authors

Beverley J. Wills, Keith L. Thompson, Mingsheng Han, H. Netzer, D. Wills, J. A. Baldwin, Gary J. Ferland, I W. A. Browne, and M. S. Brotherton 


\title{
THE HUBBLE SPACE TELESCOPE SAMPLE OF RADIO-LOUD QUASARS:
} ULTRAVIOLET SPECTRA OF THE FIRST 31 QUASARS ${ }^{1}$

\author{
Beverley J. Wills, ${ }^{2}$ Keith L. Thompson, ${ }^{2}$ Mingsheng Han, ${ }^{2,3}$ H. Netzer, ${ }^{4}$ D. Wills, ${ }^{2}$ \\ J. A. Baldwin, ${ }^{5}$ G. J. Ferland, ${ }^{6}$ I. W. A. Browne, ${ }^{7}$ and M. S. Brotherton ${ }^{2}$ \\ Received 1994 January 21; accepted 1994 March 17
}

\begin{abstract}
We report the first results from a continuing program to investigate the multifrequency spectrophotometric and other properties of a sample of about 50 radio-loud quasars in the redshift range $\sim 0.3-1.3$. Here we present spectrophotometric data of high signal-to-noise ratio ( $~ 20$ in the continuum) of the first 31 radio-loud quasars, over the wavelength range from below Ly $\alpha$ to an observed wavelength of 3250 or $4800 \AA$, obtained using the Faint Object Spectrograph on the Hubble Space Telescope. We have also made quasi-simultaneous observations to extend these spectra beyond the Balmer lines-either $\mathbf{H} \beta$ or $\mathbf{H} \alpha$-and those data will be presented in companion papers. In the ultraviolet and optical, the resolution is $300-400 \mathrm{~km} \mathrm{~s}^{-1}$ and in the infrared, about $1000 \mathrm{~km} \mathrm{~s}^{-1}$. The sample was selected by luminosity of the extended radio emission, and to cover a range of radio core-dominance, in order to test ideas relating to orientation of the continuum and emissionline regions to the observer's line of sight.

We present the ultraviolet spectra, and tabulate basic spectroscopic measurements: continuum flux densities and spectral indices, intensities and equivalent widths for all strong emission lines after deblending, as well as profile parameters such as various line widths and asymmetries. The relations between these and other parameters will be presented in detail in a later paper.

In our low-redshift sample we have good coverage from C III $\lambda 977$ to $O$ VI $\lambda 1035$, a region that is very confused by Lyman forest absorption in high-redshift quasars observed from the ground. We find that Ly $\beta$ is less than $10 \%$ of the strength of $O$ VI $\lambda 1035$. The ratio $O$ VI $\lambda 1035 / \mathrm{Ly} \alpha \sim 0.21$ supports photoionization models with high ionization and a small, dense broad-line region, although the weakness of $\mathrm{C}$ III $\lambda 977-$ typically $5 \%$ of Ly $\alpha$-limits the amount of gas with densities $\gtrsim 10^{10}-10^{11} \mathrm{~cm}^{-3}$. The $\mathrm{N}$ III $\lambda 991$ line is present at about $4 \%$ the strength of Ly $\alpha$.

In contrast to the lobe-dominant quasars, which have flat ultraviolet-optical continua (in $F_{v}$ ), all quasars with steep continua are radio core-dominant, and their broad lines tend to have lower equivalent width. Associated absorption is more prominent in the lobe-dominant quasars. Both these results are consistent with unified schemes in which a synchrotron-emitting jet is viewed at small angles to the line-of-sight in coredominant quasars, and the line-of-sight at larger angles passes through cooler gas. In addition, we find and discuss significant differences in C IV $\lambda 1549$ line asymmetries: the profiles of core-dominant quasars have stronger red wings, profiles of lobe-dominant quasars tend to be symmetric with both red and blue wings, and radio-quiet QSO profiles have stronger blue wings.
\end{abstract}

Subject headings: line: profiles - quasars: emission lines - quasars: general — radio sources: general

\section{INTRODUCTION}

The International Ultraviolet Explorer with its $45 \mathrm{~cm}$ telescope and rugged, low-resolution (FWHM $\sim 1000 \mathrm{~km} \mathrm{~s}^{-1}$ ) spectrographs, for 14 years led the investigation of ultraviolet spectra of low-redshift AGNs (Kondo 1987). For the first time,

\footnotetext{
${ }^{1}$ Based on observations with the NASA/ESA Hubble Space Telescope, obtained at the Space Telescope Science Institute, which is operated by the Association of Universities for Research in Astronomy, Inc., under NASA contract NAS 5-26555.

${ }^{2}$ McDonald Observatory and Department of Astronomy, University of Texas at Austin, Austin, TX 78712.

${ }^{3}$ Now at the Department of Astronomy, University of Wisconsin-Madison, Madison, WI 53706.

${ }^{4}$ Department of Physics and Astronomy, Tel Aviv University, Tel Aviv 69978, Israel.

${ }^{5}$ Cerro Tololo Inter-American Observatory, P.O. Box 26732, Tucson, AZ 85726.

6 Department of Physics and Astronomy, University of Kentucky, Lexington, KY 40506-0055.

${ }_{7}$ University of Manchester Nuffield Radio Astronomy Labs., Jodrell Bank, Macclesfield, Cheshire, SK11 9DL, England, UK.
}

their strong resonance lines became accessible ( Ly $\alpha, \mathrm{C}$ IV, $\mathrm{N}$ v, $\mathrm{Si}$ IV, $\mathrm{Mg}$ II, etc.), as well as the high-energy (ionizing) continuum, hitherto seen only in high-redshift QSOs. The " Ly $\alpha / H \beta$ problem "was established and investigated; the problem of the great strengths of low-ionization lines (e.g., Fe II) relative to the ionizing continuum was revealed (e.g., Netzer 1985); and the importance of reddening was questioned. There were tantalizing hints of differences in broad line widths and redshifts within individual spectra. All these indicated a more complex structure in the inner regions of the most luminous AGNs. In addition, it was becoming clear that the radio jets defined an axis of symmetry for the central engine, raising the question of how the structure of the continuum and emission-line regions might be related to this fundamental direction. Further progress required the comparison of line profiles of the strong and weak UV lines with improved signal-to-noise ratio and wavelength resolution. The Faint Object Spectrograph on board the Hubble Space Telescope, with improved resolution (230-350 $\mathrm{km} \mathrm{s}^{-1} \mathrm{FWHM}$ ) and light-gathering power, now provides this capability - as well as the capability of observing fainter QSOs, 
hence allowing the observation of carefully defined samples. We are investigating such a sample, and this paper describes our initial measurements and some results.

The main observational goal of our $H S T$-based program is to produce the definitive sample of spectra of $\sim 50$ radio-loud quasars, each over the rest wavelength from range below Ly $\alpha$ to beyond $H \beta$, enabling determination of the continuum over a wide wavelength range, and the comparison of the ultraviolet lines (e.g., Ly $\alpha, \mathrm{N} v \lambda 1240, \lambda 1400, \mathrm{C}$ IV $\lambda 1549, \mathrm{C}$ III] $\lambda 1909$, Mg II $\lambda 2798$, Fe II $\lambda \lambda 2000-3000)$ with, for example, hydrogen Balmer lines, $\mathrm{He}$ II $\lambda 4686, \mathrm{Fe}$ II $\lambda 4570$ and $\lambda 5300$, etc. (and $\mathrm{Pa} \beta$ for a significant subset). Ultraviolet data obtained with the Hubble Space Telescope's Faint Object Spectrograph (HST's FOS) are being complemented by quasi-simultaneous optical and infrared spectroscopy from McDonald Observatory, KPNO, UKIRT, and CTIO. This is the only large well-defined sample being observed by $H S T$ to investigate the intrinsic properties of QSOs. (We refer to radio-loud QSOs as "quasars").

A major goal of our program is to test the dependence of spectroscopic properties on inclination of the axis of the central engine (defined by the radio axis). We have therefore chosen our sample to cover a wide range of radio-core dominance-a measure of the inclination of the central engine's axis to the line of sight-while constraining the range in extended radio luminosity, which is inclination-independent. Thus the two great advantages of our data set are the wide wavelength range covering high- and low-ionization lines and a large part of the continuum, and its design to measure aspect dependence in a way free of luminosity bias.

Here we present the available data-31 spectra from $H S T$ Cycles 1 and 2 (observations begun in 1991 August). We have already used some of these spectral data to compare the strengths of ultraviolet and optical lines from the narrow-line region (NLR) (Wills et al. 1993a), and to compare the continuum and unusual emission-line spectrum of the blazar 3C 279 with fortuitously simultaneous gamma-ray observations with the Egret telescope on the Compton Gamma Ray Observatory (Netzer et al. 1994).

Subsequent papers will present further $H S T$ ultraviolet data, the optical and infrared data, and compare emission-line strengths, profiles and profile shifts, and continuum shape, and will use new and existing radio and $\mathrm{X}$-ray data to investigate basic questions such as the structure of the broad-line region (BLR), the dependence of line strengths and ratios on luminosity (the Baldwin effect), the relations among IR, optical, UV and X-ray luminosity, etc., and so the sample will be used for investigating other spectroscopic ideas and problems besides the inclination dependence. The present sample will be a useful starting point for investigations by others-by extending the sample (1) to complete a 3CR sample, (2) to fainter optical limits, and (3) to different ranges in extended radio luminosity (e.g., radio galaxies), and (4) for comparison with radio-quiet samples.

The selection of the sample and the observations are described in $\$ \$ 2$ and 3. The calibrations and corrections applied to the data are summarized briefly in $\S 4$, and $\S 5$ discusses continuum measurement, and line deblending and measurement. The results of line measurements are also presented in $\S 5$-fluxes, equivalent widths, and line profile measurements for the strongest lines, as well as relative line strengths or upper limits for 16 lines commonly identified in the ultraviolet spectra of quasars. These sections are followed by a brief discussion of some results from this work (§ 6).

\section{THE SAMPLE}

Our Cycle 1 sample was originally a low-frequency fluxlimited sample from the 3CR catalog with complete optical identifications, and $z<1.8$, selected over a limited range of an orientation-independent property, the radio lobe luminosity, $L_{\text {ext }}$. The range of $\log L_{\text {ext }}$ is 26.5-27.6, where $L_{\text {ext }}$ is calculated in ergs $\mathrm{s}^{-1} \mathrm{~Hz}^{-1}$ at $6 \mathrm{~cm}$ rest wavelength, assuming $q_{0}=0$, $H_{0}=50 \mathrm{~km} \mathrm{~s}^{-1} \mathrm{Mpc}^{-1}$. This sample was supplemented by core-dominant quasars selected over the same $L_{\text {ext }}$ interval. After HST's spherical aberration was discovered, with consequent reduced throughput of the combined HST and FOS, the faintest quasars were replaced by brighter objects $(V \lesssim 18)$, selected to retain sample size and to achieve the same scientific goals, with the same range in lobe luminosity, or selected as quasar pairs - a radio core- and a lobe-dominated quasar, each matched within 0.5 in $\log L_{\text {ext }}$, and 0.2 in $\log z$. Our sample consists of roughly equal numbers of lobe- and core-dominant quasars with a wide range in the ratio, $R$, of core to extended radio emission, from about 0.01 to 100 (at $6 \mathrm{~cm}$ rest wavelength) and a similar range in X-ray and radio core luminosity.

The choice of defining parameters has several advantages. The low $L_{\text {ext }}$ favors small $z$. This means brighter quasars and therefore a more completely identified sample. They are easier to observe at ultraviolet, optical, IR, X-ray wavelengths, and have more information available from literature and other sources. The lower redshift also means better linear resolution for imaging, especially at radio wavelengths. The low redshifts also allow a comparison with AGNs of lower luminosity, for example, Seyfert 1 galaxies and broad-line radio galaxies. Because the quasars are relatively low redshift and radio loud, most, if not all, are expected to have $R O S A T$ X-ray data.

Out of our sample of $\sim 50, H S T$ successfully observed 31 quasars in Cycles 1 and 2. In Cycle 3 only two were observed successfully, and we are observing the remainder in Cycle 4. Other HST programs have observed, or plan to observe, five other sources from our sample. These additional sources will have less certain photometric calibration as they use the $1^{\prime \prime}$ aperture, and also will not all have quasi-simultaneous ground-based spectroscopy (although we are attempting this). Basic data for Cycle 1 and 2 objects are given in Tables 1 and 2.

\section{OBSERVATIONS}

A log of the observations is given in Table 1, including positions measured from the GSSS (Guide Star Selection System) survey plates (Lasker 1990), using the GSSS Astrometric Support Package at the Space Telescope Science Institute. These $\mathrm{J} 2000$ coordinates are in the GSSS reference frame used by $H S T$ and are internally accurate to $\sim 0.3-0.15 \mathrm{rms}$. The table gives a brief description of the FOS configuration used, the observation date and exposure time, and an identifying "root" name as used in the HST archives. HST's FOS is described in detail by Ford \& Hartig (1990) and Kinney (1992).

We used the FOS high-resolution grating settings $\mathrm{G} 130 \mathrm{H}$, $\mathrm{G} 190 \mathrm{H}, \mathrm{G} 270 \mathrm{H}$, and $\mathrm{G} 400 \mathrm{H}$, centered at about 1350, 1950, 2750 , and $4000 \AA$, respectively, to cover the wavelength range from below $L y \alpha$ to above the atmospheric cutoff-to observed wavelengths of either $\sim 3250$ or $\sim 4800 \AA$. The resolution of the spectrograph was $\sim 1300$. We used the Red- or Blue-side Digicon detectors as specified in Table 1. For each grating setup an electron image from a photocathode is magnetically focused onto a Digicon array of 512 diodes each $50 \mu \mathrm{m}$ wide $\times 200 \mu \mathrm{m}$ perpendicular to the dispersion direction. The elec- 
TABLE 1

LOG OF HST OBSERVATIONS

\begin{tabular}{|c|c|c|c|c|c|c|c|c|c|}
\hline Target & Alias & Plate Id & $\begin{array}{c}\mathrm{RA} \\
(2000)\end{array}$ & $\begin{array}{c}\text { DEC } \\
(2000)\end{array}$ & Side & Grating & $\begin{array}{r}\text { Exp.T } \\
(\mathrm{sec})\end{array}$ & $\begin{array}{l}\text { Date } \\
\text { (UT) }\end{array}$ & Root \\
\hline \multirow[t]{2}{*}{ B2 $0110+29$} & \multirow[t]{4}{*}{$0110+297$} & \multirow[t]{2}{*}{$00 \mathrm{DV}$} & \multirow[t]{2}{*}{011324.21} & \multirow[t]{2}{*}{295815.8} & $\mathrm{RD}$ & $\mathrm{G} 190 \mathrm{H}$ & 936 & 1992 Sep 06 & $\mathrm{Y}_{12 \mathrm{~B} 0102 \mathrm{~T}^{\mathrm{a}}}$ \\
\hline & & & & & $\mathrm{RD}$ & $\mathrm{G} 270 \mathrm{H}$ & 438 & 1992 Sep 06 & $\mathrm{Y}_{12 \mathrm{~B} 0103 \mathrm{~T}^{\mathrm{a}}}$ \\
\hline \multirow{2}{*}{ PKS 0112-01 } & & \multirow{2}{*}{ ooWT } & \multirow{2}{*}{$01 \quad 15 \quad 17.12$} & \multirow[t]{2}{*}{-012704.9} & $\mathrm{RD}$ & $\mathrm{G} 270 \mathrm{H}$ & 918 & 1991 Sep 06 & Y0PE0102T \\
\hline & & & & & $\mathrm{RD}$ & $\mathrm{G} 400 \mathrm{H}$ & 732 & 1991 Sep 06 & Y0PE0103T \\
\hline \multirow[t]{2}{*}{$3 \mathrm{C} 47.0$} & \multirow[t]{5}{*}{$0133+207$} & \multirow[t]{2}{*}{$00 \mathrm{FG}$} & \multirow[t]{2}{*}{013624.47} & 205726.5 & RD & $\mathrm{G} 190 \mathrm{H}$ & 1884 & 1992 Aug 30 & Y12B0202T \\
\hline & & & & & $\mathrm{RD}$ & $\mathrm{G} 270 \mathrm{H}$ & 912 & 1992 Aug 30 & Y12B0203T \\
\hline PKS 0403-13 & & $02 \mathrm{NG}$ & 040533.98 & -130814.1 & $\mathrm{RD}$ & G190H & 1410 & 1991 Oct 11 & YOPE0202T \\
\hline & & & & & $\mathrm{RD}$ & $\mathrm{G} 270 \mathrm{H}$ & 756 & 1991 Oct 11 & Y0PE0203T \\
\hline & & & & & $\mathrm{RD}$ & $\mathrm{G} 400 \mathrm{H}$ & 534 & 1991 Oct 12 & YoPE0204T \\
\hline $3 C 175$ & $0710+118$ & $02 \mathrm{UV}$ & 071302.39 & 114615.5 & $\mathrm{RD}$ & $\mathrm{G} 190 \mathrm{H}$ & 1092 & $1991 \mathrm{Dec} 03$ & Y0PE0302T \\
\hline & & & & & $\mathrm{RD}$ & $\mathrm{G} 270 \mathrm{H}$ & 720 & 1991 Dec 03 & Y0PE0303T \\
\hline & & & & & $\mathrm{RD}$ & $\mathrm{G} 400 \mathrm{H}$ & 486 & $1991 \mathrm{Dec} 03$ & Y0PE0304T \\
\hline $3 \mathrm{C} 186$ & $0740+380$ & $031 \mathrm{M}$ & 074417.47 & 375316.9 & $\mathrm{RD}$ & $\mathrm{G} 270 \mathrm{H}$ & 1080 & $1991 \mathrm{Dec} 03$ & Y0PE0402T \\
\hline & & & & & $\mathrm{RD}$ & $\mathrm{G} 400 \mathrm{H}$ & 846 & 1991 Dec 03 & Y0PE0403T \\
\hline $3 \mathrm{C} 207$ & $0838+133$ & $028 \mathrm{H}$ & 084047.56 & $1312 \quad 23.7$ & $\mathrm{RD}$ & $\mathrm{G} 190 \mathrm{H}$ & 1254 & 1991 Dec 04 & YoPE0502T \\
\hline & & & & & $\mathrm{RD}$ & $\mathrm{G} 190 \mathrm{H}$ & 1260 & 1991 Dec 04 & YoPE0503T \\
\hline & & & & & $\mathrm{RD}$ & $\mathrm{G} 270 \mathrm{H}$ & 748 & 1991 Dec 04 & Y0PE0504T \\
\hline & & & & & $\mathrm{RD}$ & $\mathrm{G} 270 \mathrm{H}$ & 740 & 1991 Dec 04 & Y0PE0505T \\
\hline & & & & & $\mathrm{RD}$ & $\mathrm{G} 400 \mathrm{H}$ & 1230 & 1991 Dec 04 & Y0PE0506T \\
\hline PKS 0859-14 & & OOFG & 090216.80 & -141531.1 & $\mathrm{RD}$ & $\mathrm{G} 270 \mathrm{H}$ & 450 & 1993 Mar 05 & Y12B0302T \\
\hline $3 \mathrm{C} 215$ & $0903+169$ & 0204 & 090631.86 & 164612.2 & $\mathrm{RD}$ & $\mathrm{G} 190 \mathrm{H}$ & 1830 & 1992 May 01 & Y0PE0602T \\
\hline & & & & & RD & $\mathrm{G} 190 \mathrm{H}$ & 1830 & 1992 May 01 & YoPE0603T \\
\hline & & & & & $\mathrm{RD}$ & $\mathrm{G} 190 \mathrm{H}$ & 1830 & 1992 May 01 & YOPE0604T \\
\hline & & & & & $\mathrm{RD}$ & $\mathrm{G} 270 \mathrm{H}$ & 726 & 1992 May 01 & Y0PE0605T \\
\hline & & & & & $\mathrm{RD}$ & $\mathrm{G} 270 \mathrm{H}$ & 720 & 1992 May 01 & Y0PE0606T \\
\hline & & & & & $\mathrm{RD}$ & $\mathrm{G} 400 \mathrm{H}$ & 1134 & 1992 May 01 & YoPE0607T \\
\hline $3 C 216.0$ & $0906+430$ & $021 \mathrm{G}$ & 090933.53 & 425347.0 & $\mathrm{RD}$ & $\mathrm{G} 190 \mathrm{H}$ & 1688 & 1992 Dec 28 & Y12B0402T \\
\hline & & & & & $\mathrm{RD}$ & $\mathrm{G190H}$ & 1690 & 1992 Dec 28 & Y12B0403T \\
\hline & & & & & $\mathrm{RD}$ & $\mathrm{G} 270 \mathrm{H}$ & 818 & 1992 Dec 28 & $404 \mathrm{~T}$ \\
\hline & & & & & $\mathrm{RD}$ & $\mathrm{G} 270 \mathrm{H}$ & 820 & 1992 Dec 29 & Y12B0405T \\
\hline B2 0923+39 & $0923+392$ & 01BS & 092703.05 & $3902 \quad 20.9$ & $\mathrm{RD}$ & $\mathrm{G} 190 \mathrm{H}$ & 2082 & 1991 Dec 27 & YoPE0702T $^{\mathrm{a}}$ \\
\hline & & & & & RD & $\mathrm{G} 270 \mathrm{H}$ & 1206 & 1991 Dec 27 & YoPE0703T $^{\mathrm{a}}$ \\
\hline & & & & & $\mathrm{RD}$ & $\mathrm{G} 400 \mathrm{H}$ & 1002 & 1991 Dec 27 & YOPE0704T $^{\mathrm{a}}$ \\
\hline & & & & & $\mathrm{RD}$ & $\mathrm{G} 190 \mathrm{H}$ & 2185 & 1993 Jan 24 & $\mathrm{Y} 1170102 \mathrm{~T}$ \\
\hline & & & & & $\mathrm{RD}$ & $\mathrm{G} 270 \mathrm{H}$ & 1206 & 1993 Jan 24 & Y1170103T \\
\hline & & & & & RD & $\mathrm{G} 400 \mathrm{H}$ & 1002 & 1993 Jan 24 & Y1170104T \\
\hline $4 \mathrm{C} 55.17$ & $0954+556$ & 0009 & 095738.16 & $\begin{array}{lll}55 & 22 & 57.7\end{array}$ & $\mathrm{RD}$ & G190H & 1928 & 1993 Jan 20 & Y1170302T \\
\hline & & & & & $\mathrm{RD}$ & $\mathrm{G190H}$ & 1930 & $1993 \operatorname{Jan} 20$ & Y1170303T \\
\hline & & & & & RD & $\mathrm{G} 270 \mathrm{H}$ & 1650 & 1993 Jan 20 & Y1170304T \\
\hline PKS 1103-006 & & $04 \mathrm{I} 7$ & 110631.75 & -005253.4 & $\mathrm{RD}$ & $\mathrm{G} 190 \mathrm{H}$ & 498 & 1992 Dec 29 & Y12B0502T \\
\hline & & & & & $\mathrm{RD}$ & $\mathrm{G} 270 \mathrm{H}$ & 240 & 1992 Dec 29 & Y12B0503T \\
\hline $3 C 254$ & $1111+408$ & 01QX & 111438.70 & 403720.1 & $\mathrm{RD}$ & $\mathrm{G} 190 \mathrm{H}$ & 1110 & 1992 Apr 15 & Y0PE0802T \\
\hline & & & & & RD & $\mathrm{G} 190 \mathrm{H}$ & 1110 & 1992 Apr 15 & Y0PE0803T \\
\hline & & & & & RD & $\mathrm{G} 270 \mathrm{H}$ & 1374 & 1992 Apr 15 & YOPE0804T \\
\hline & & & & & $\mathrm{RD}$ & $\mathrm{G} 400 \mathrm{H}$ & 1152 & 1992 Apr 15 & YOPE0805T \\
\hline PKS 1127-14 & & $02 \mathrm{MF}$ & 113007.02 & -144927.6 & $\mathrm{RD}$ & $\mathrm{G} 270 \mathrm{H}$ & 534 & 1993 Jan 01 & Y12B0602T \\
\hline $3 \mathrm{C} 263$ & $1137+660$ & $01 \mathrm{RM}$ & 113957.06 & 654749.5 & $\mathrm{RD}$ & $\mathrm{G} 190 \mathrm{H}$ & 534 & 1991 Nov 06 & Y0PE0902T \\
\hline & & & & & RD & $\mathrm{G} 270 \mathrm{H}$ & 276 & 1991 Nov 06 & Y0PE0903T \\
\hline & & & & & $\mathrm{RD}$ & $\mathrm{G} 400 \mathrm{H}$ & 204 & 1991 Nov 06 & YOPE0904T \\
\hline $3 \mathrm{C} 277.1$ & $1250+568$ & 01R1 & $1252 \quad 26.29$ & 563420.4 & $\mathrm{RD}$ & $\mathrm{G} 190 \mathrm{H}$ & 1986 & 1991 Nov 02 & YOPE0A02T \\
\hline & & & & & $\mathrm{RD}$ & $\mathrm{G} 270 \mathrm{H}$ & 1122 & 1991 Nov 02 & Y0PE0A03T \\
\hline & & & & & $\mathrm{RD}$ & $\mathrm{G} 400 \mathrm{H}$ & 864 & 1991 Nov 02 & YOPE0A04T \\
\hline $3 \mathrm{C} 279$ & $1253-055$ & $024 \mathrm{R}$ & 125611.15 & -054721.6 & $\mathrm{RD}$ & G190H & 1270 & 1992 Apr 08 & Y0PE0B02T \\
\hline & & & & & $\mathrm{RD}$ & $\mathrm{G} 190 \mathrm{H}$ & 1280 & 1992 Apr 08 & YOPE0B03T \\
\hline & & & & & RD & $\mathrm{G} 270 \mathrm{H}$ & 1278 & $1992 \mathrm{Apr} 08$ & Y0PE0B04T \\
\hline & & & & & $\mathrm{RD}$ & $\mathrm{G} 400 \mathrm{H}$ & 918 & 1992 Apr 08 & Y0PE0B05T \\
\hline $3 C 288.1$ & $1340+606$ & 01R0 & 134213.24 & 602142.9 & $\mathrm{RD}$ & $\mathrm{G} 270 \mathrm{H}$ & 884 & 1993 Apr 06 & Y12B0702T \\
\hline & & & & & $\mathrm{RD}$ & G270H & 880 & 1993 Apr 06 & Y12B0703T \\
\hline PKS $1354+19$ & $4 \mathrm{C} 19.44$ & 019M & 135704.48 & 191906.5 & $\mathrm{RD}$ & $\mathrm{G} 190 \mathrm{H}$ & 492 & 1993 Apr 29 & Y12B0802T \\
\hline & & & & & $\mathrm{RD}$ & $\mathrm{G} 270 \mathrm{H}$ & 222 & 1993 Apr 29 & Y12B0803T \\
\hline & & & & & $\mathrm{RD}$ & $\mathrm{G} 400 \mathrm{H}$ & 174 & 1993 Apr 29 & Y12B0804T \\
\hline $3 \mathrm{C} 323.1$ & $1545+210$ & 0280 & 154743.53 & 205216.4 & $\mathrm{RD}$ & $\mathrm{G} 190 \mathrm{H}$ & 384 & 1992 Apr 08 & YOPEOD02T \\
\hline
\end{tabular}


TABLE 1-Continued

\begin{tabular}{|c|c|c|c|c|c|c|c|c|c|}
\hline Target & Alias & Plate Id & $\begin{array}{c}\mathrm{RA} \\
(2000)\end{array}$ & $\begin{array}{c}\text { DEC } \\
(2000)\end{array}$ & Side & Grating & $\begin{array}{r}\text { Exp.T } \\
(\mathrm{sec})\end{array}$ & $\begin{array}{l}\text { Date } \\
\text { (UT) }\end{array}$ & Root \\
\hline & & & & & $\mathrm{RD}$ & $\mathrm{G} 270 \mathrm{H}$ & 225 & 1992 Apr 08 & YoPE0D03T \\
\hline & & & & & $\mathrm{RD}$ & $\mathrm{G} 400 \mathrm{H}$ & 156 & 1992 Apr 08 & YOPEOD04T \\
\hline & & & & & BL & $\mathrm{G} 130 \mathrm{H}$ & 1150 & 1992 Apr 10 & YoPE0C02T \\
\hline & & & & & $\mathrm{BL}$ & $\mathrm{G} 130 \mathrm{H}$ & 1160 & 1992 Apr 10 & Y0PE0C03T \\
\hline \multirow[t]{2}{*}{ B2 $1555+33$} & $1555+332$ & 01RN & $15 \quad 5729.95$ & 330446.7 & RD & $\mathrm{G} 270 \mathrm{H}$ & 1018 & 1993 May 22 & Y12B0902T \\
\hline & & & & & $\mathrm{RD}$ & $\mathrm{G} 270 \mathrm{H}$ & 1010 & 1993 May 22 & Y12B0903T \\
\hline \multirow[t]{2}{*}{ DA 406} & $1611+343$ & $01 \mathrm{RW}$ & 161341.10 & 341248.0 & RD & $\mathrm{G} 270 \mathrm{H}$ & 876 & 1992 Apr 04 & YOPEOF02T \\
\hline & & & & & $\mathrm{RD}$ & $\mathrm{G} 400 \mathrm{H}$ & 690 & 1992 Apr 04 & Y0PE0F03T \\
\hline \multirow[t]{3}{*}{$3 \mathrm{C} 334$} & $1618+177$ & $01 \mathrm{GC}$ & 162021.80 & 173623.9 & RD & $\mathrm{G} 190 \mathrm{H}$ & 648 & 1991 Sep 07 & YOPE0G02T \\
\hline & & & & & $\mathrm{RD}$ & $\mathrm{G} 270 \mathrm{H}$ & 345 & 1991 Sep 07 & Y0PE0G03T \\
\hline & & & & & $\mathrm{RD}$ & $\mathrm{G} 400 \mathrm{H}$ & 252 & 1991 Sep 07 & YOPEOG04T \\
\hline \multirow[t]{3}{*}{ OS 562} & $1637+574$ & $00 \mathrm{FG}$ & 163813.46 & $\begin{array}{lll}57 & 20 & 23.9\end{array}$ & RD & $\mathrm{G} 190 \mathrm{H}$ & 1314 & 1992 Aug 11 & Y1170502T \\
\hline & & & & & RD & $\mathrm{G} 270 \mathrm{H}$ & 564 & 1992 Aug 11 & Y1170503T \\
\hline & & & & & RD & $\mathrm{G} 400 \mathrm{H}$ & 450 & 1992 Aug 11 & Y1170504T \\
\hline \multirow[t]{3}{*}{$3 \mathrm{C} 345$} & $1641+399$ & O0CL & 164258.78 & 394836.9 & $\mathrm{RD}$ & $\mathrm{G} 190 \mathrm{H}$ & 426 & 1992 Jun 07 & YOPE0I02T \\
\hline & & & & & $\mathrm{RD}$ & $\mathrm{G} 270 \mathrm{H}$ & 225 & 1992 Jun 07 & YOPEOI03T \\
\hline & & & & & $\mathrm{RD}$ & $\mathrm{G} 400 \mathrm{H}$ & 189 & 1992 Jun 07 & YOPE0I04T \\
\hline \multirow[t]{5}{*}{ B2 $2201+31 \mathrm{~A}$} & $2201+315$ & 02UD & 220315.02 & 314537.7 & $\mathrm{BL}$ & $\mathrm{G} 130 \mathrm{H}$ & 1390 & 1991 Sep 07 & YoPE0J02T \\
\hline & & & & & $\mathrm{BL}$ & $\mathrm{G} 130 \mathrm{H}$ & 1400 & 1991 Sep 07 & Y0PE0J03T \\
\hline & & & & & BL & $\mathrm{G} 190 \mathrm{H}$ & 1104 & 1991 Sep 07 & YOPE0J04T \\
\hline & & & & & $\mathrm{RD}$ & $\mathrm{G} 270 \mathrm{H}$ & 222 & $1991 \mathrm{Sep} 06$ & YOPEOK02T \\
\hline & & & & & $\mathrm{RD}$ & $\mathrm{G} 400 \mathrm{H}$ & 132 & 1991 Sep 06 & YOPEOK03T \\
\hline \multirow{9}{*}{ PKS 2216-03 } & & $02 \mathrm{O} 6$ & $22 \quad 1852.08$ & -033537.4 & RD & $\mathrm{G} 190 \mathrm{H}$ & 666 & 1991 Sep 06 & YOPEOL02T \\
\hline & & & & & RD & $\mathrm{G} 270 \mathrm{H}$ & 486 & 1991 Sep 06 & YOPEOL03T $^{a}$ \\
\hline & & & & & RD & $\mathrm{G} 400 \mathrm{H}$ & 294 & 1991 Sep 06 & YOPEOL04T \\
\hline & & & & & $\mathrm{RD}$ & $\mathrm{G190H}$ & 666 & 1992 Aug 27 & $\mathrm{Y} 1170202 \mathrm{~T}^{\mathrm{a}}$ \\
\hline & & & & & RD & $\mathrm{G} 270 \mathrm{H}$ & 486 & 1992 Aug 28 & $\mathrm{Y} 1170203 \mathrm{~T}^{\mathrm{a}}$ \\
\hline & & & & & RD & $\mathrm{G} 400 \mathrm{H}$ & 294 & 1992 Aug 28 & $\mathrm{Y}_{1170204 \mathrm{~T}^{\mathrm{a}}}$ \\
\hline & & & & & RD & $\mathrm{G} 190 \mathrm{H}$ & 666 & 1993 Oct 03 & Y1EM0102P \\
\hline & & & & & RD & $\mathrm{G} 270 \mathrm{H}$ & 486 & 1993 Oct 03 & Y1EM0103P \\
\hline & & & & & RD & $\mathrm{G} 400 \mathrm{H}$ & 294 & 1993 Oct 03 & Y1EM0104P \\
\hline \multirow[t]{3}{*}{$3 \mathrm{C} 446$} & $2223-052$ & $02 \mathrm{O} 6$ & $22 \quad 2547.31$ & -045701.4 & RD & $\mathrm{G} 270 \mathrm{H}$ & 966 & 1991 Sep 11 & YOPE0M02T \\
\hline & & & & & RD & $\mathrm{G} 270 \mathrm{H}$ & 960 & 1991 Sep 11 & YOPEOM03T \\
\hline & & & & & $\mathrm{RD}$ & $\mathrm{G} 400 \mathrm{H}$ & 147 & $1991 \mathrm{Sep} 11$ & YOPEOM04T \\
\hline \multirow[t]{2}{*}{ CTA 102} & $2230+114$ & $02 \mathrm{CV}$ & 223236.45 & 114350.7 & RD & $\mathrm{G} 270 \mathrm{H}$ & 954 & 1991 Sep 12 & YOPEONO2T \\
\hline & & & & & RD & $\mathrm{G} 400 \mathrm{H}$ & 648 & 1991 Sep 12 & YOPE0N03T \\
\hline \multirow[t]{3}{*}{$3 C 454.3$} & $2251+158$ & 00GO & 225357.77 & 160853.3 & RD & $\mathrm{G} 190 \mathrm{H}$ & 504 & $1991 \mathrm{Sep} 11$ & YOPE0O02T \\
\hline & & & & & RD & $\mathrm{G} 270 \mathrm{H}$ & 954 & 1991 Sep 12 & YOPE0O03T \\
\hline & & & & & RD & $\mathrm{G} 400 \mathrm{H}$ & 648 & $1991 \mathrm{Sep} 12$ & YoPE0004T \\
\hline \multirow[t]{4}{*}{ PKS 2251+11 } & & 00JD & 225410.44 & 113638.9 & $\mathrm{BL}$ & G130H & 1980 & 1991 Sep 06 & YOPE0P02T \\
\hline & & & & & $\mathrm{BL}$ & $\mathrm{G} 190 \mathrm{H}$ & 732 & 1991 Sep 07 & YOPE0P03T \\
\hline & & & & & RD & $\mathrm{G} 270 \mathrm{H}$ & 162 & $1991 \mathrm{Sep} 06$ & YOPE0Q02T \\
\hline & & & & & $\mathrm{RD}$ & $\mathrm{G} 400 \mathrm{H}$ & 141 & 1991 Sep 06 & YOPE0Q03T \\
\hline
\end{tabular}

${ }^{a}$ FOS Binary Acquisition failed.

tron image is stepped in 200.25 -diode intervals so that each part of the spectrum is sampled four times by each of five diodes, resulting in an image of $516 \times 4=2064$ pixels. Dispersions for the above grating setups are $0.25,0.36,0.51$, and 0.75 $\AA /$ pixel. The 4 . $3 \times 4$ ".3 aperture was used for maximum throughput. In the direction perpendicular to the dispersion this aperture is effectively limited to 1.4 by the length of the Digicon diodes, giving an effective aperture throughput of about $0.5-0.7$ from 1300 to $4000 \AA$ (because of HST's spherical aberration). The targets were centered in the aperture using a Binary Acquisition, and the integrations made in the Accum mode (Ford \& Hartig 1990). Centering and tracking is generally accurate to $\sim 0$ ". 1 , so spectral resolution is limited by the spectrograph itself, by the point-spread function of $H S T$, and by GIM (see $\$ 4.1)$. The effective resolution for a point source is 1.5 diodes FWHM-or 6 pixels (i.e., $\sim 350 \mathrm{~km} \mathrm{~s}^{-1}$ ).

The wavelength scale, resolution, and the photometric accuracy of the spectra are affected by geomagnetic image motion
(GIM, Koratkar 1994). This image motion is caused by a partial breakdown of the Digicons' magnetic shielding, so that peak-to-peak image shifts of up to $70 \mu \mathrm{m}$ occur as the spacecraft orbits, as a result of the changing angle between the Earth's magnetic field and that of the Digicon tube. Fortunately, compensating shifts can be applied to the wavelength scale because data are read out at intervals that are short compared with the 90 minute orbit -2 and 4 minutes for the Red and Blue Digicons respectively. The effect is about three times smaller for the Blue tube than for the Red, and is unimportant for our Blue side spectra.

The exposure times were estimated to give a signal-to-noise ratio of at least 21 per resolution element in the continuum, in the region of important emission lines (Ly $\alpha, \mathrm{C}$ IV $\lambda 1549, \mathrm{C}$ III] $\lambda 1909$ and $\mathrm{Mg}$ II 22798). These estimates were based on a composite quasar spectrum derived from $I U E$ and McDonald Observatory spectrophotometry of several radio-loud quasars. Figure 1 shows the expected count rate per diode ( 4 pixels) for 


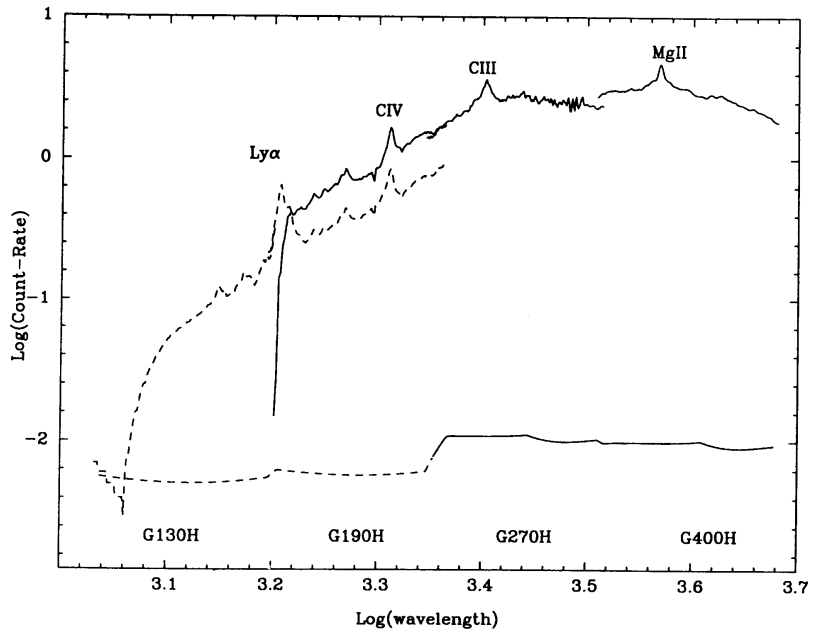

Fig. 1.-Example of the predicted count rates (counts $\mathrm{s}^{-1}$ ) for a bright $(V \sim 15.8)$, low-redshift $(z=0.323)$ quasar, PKS $2251+11$. Coordinates are logarithmic to enable sensible scaling of the full wavelength range and the (modeled) detector background count rate. Filled and dashed lines are for the red and blue Digicon detectors. Note that for observations (of $L y \alpha$ ) near 1608 $\AA$, the blue Digicon has significant sensitivity but the red does not.

The prediction is based on a composite spectrum formed from IUE and McDonald Observatory data, corrected for appropriate Galactic reddening, $V$-band magnitude, and redshift, which is then converted to count rate using FOS Handbook information on telescope and spectrograph throughput (for the 4 ".3 aperture), and detector response.

a Cycle 1 target, as well as the expected count rates from detector background. We used the Blue Digicon rather than the Red for G190H if an important emission line fell between about 1550 and $1700 \AA$, because the response of the Red Digicon declines rapidly there. For Cycle 2, we used G400H only when important emission lines fell close to the atmospheric cutoff and so could not be observed accurately from the ground.

We are monitoring the photometric variability of our sample quasars at McDonald Observatory, with additional photometry from Wise Observatory, Tel Aviv University, and CTIO, a program that gives us information on changes in optical flux density for improved estimates of $H S T$ exposure times (and for more astronomical reasons).

\section{REDUCTIONS}

Appropriate flat-field- and GIM-corrected calibrated data became available through STScl's standard pipeline processing in 1992 May. Calibration was by the standard CALFOS "task" in the IRAF/STSDAS package. This task corrects the raw counts to flux density. It takes into account diodes that have been disabled at the spacecraft, corrects for the GIM wavelength shifts, subtracts a default instrumental background, divides by normalized flat fields derived from observations of white dwarf stars obtained closest in time to the quasar observations, and computes a wavelength scale accurate to about 0.1 diodes. The instrumental count rate is then corrected to flux density units. Finally, spectra from different grating settings are combined and corrected for Galactic extinction. Details are given below.

\subsection{Geomagnetically Induced Image Motion (GIM)}

For a single observation composed of several 2 or 4 minute readouts, the pipeline process shifts each readout (in the disper- sion direction only), by an amount based on model calculations of the Earth's magnetic field. The shifts within a 2 or 4 minute integration cannot be corrected but our resolution (6 pixel FWHM) is degraded overall by less than $5 \%$ (Junkkarinen et al. 1992). The GIM also degrades the photometric accuracy $(\S 4.5)$.

\subsection{Background}

Exceeding the natural diffuse Galactic background, zodiacal light, airglow, and scattered light internal to the FOS, is a burst-noise background induced by cosmic rays in the detector faceplate (Kinney 1992; see also Ford \& Hartig 1990; Lyons et al. 1992a, b). Electronic dark count rate is negligible. A default background is subtracted, taking into account the geomagnetic position of the telescope at the time of observation. This is typically a few percent of our signal, except for $3 C 216$, for which the background was almost comparable to the signal. It is now suspected that a default background 30\% larger is more appropriate (Rosa 1993), but the present reductions use the earlier estimate.

Scattered light, probably from the grating, can be a significant contaminant for objects with very red spectral energy distributions (Kinney \& Bohlin 1993; Rosa 1993; Ayres 1993). A check on the background arising from scattered light within the spectrograph is given by observing the signal in a region of no sensitivity to the dispersed light (because of optical cutoffs). Such a region occurs at the short wavelength end of the G190H red spectrum, between pixels 2040 and 2059 (1582-1610 $\AA$ ) (Kinney \& Bohlin 1993), but we detect no significant signal here for individual objects. There is a small, significant signal when summed over many quasar spectra, but it amounts to less than a few percent of the smallest astronomical signal in this grating setting, so we have ignored it.

\subsection{Flat-Field Correction}

The diode-to-diode sensitivity variations of the Digicons are determined from observations of spectra of bright stars with smooth continua, usually white dwarfs (Anderson 1992). The flat fields seem to be time variable, especially for the Red Digicon between 1800 and $2100 \AA$ where there are large spikes and dips; they are also dependent on the aperture selected, and position of the spectrum on the diodes (Jannuzi \& Hartig 1994; Keyes 1994). We have used the flat-field calibration files determined from the calibration observation closest in time to that of our individual targets. Our data were reprocessed after the correction of the software error announced 1993 February 15 (Keyes, STScI notice). Fortunately both our quasar observations and the flat-field observations used the same 4.3 aperture. We examined our final spectra in the regions of large spikes or dips in the flat fields, and found no evidence of spurious features.

\subsection{Wavelength Calibration}

We used the cubic polynomial dispersion relation provided in the FOS "pipeline." This was determined from an internal calibration lamp, and agrees with the external scale determined from the emission line star AU Mic, to \pm 0.1 diodes (Kriss, Blair, \& Davidsen 1992). The internal accuracy of wavelength calibration, after correction for GIM, is thought to be at the level of $\sim 0.25$ diode, or roughly $50 \mathrm{~km} \mathrm{~s}^{-1}$, and the external accuracy 0.4 diodes (Bohlin \& Cox 1992). 
TABLE 2

Basic Data and Strong Line Parametersa ${ }^{a}$

\begin{tabular}{|c|c|c|c|c|c|c|c|c|c|}
\hline \multirow[b]{2}{*}{ Name } & \multirow[b]{2}{*}{$\begin{array}{c}\mathrm{z} \\
\log \mathrm{R} \\
\mathrm{V} \\
\mathrm{A}_{B} \\
\log \mathrm{Le} \\
\alpha_{u v}\end{array}$} & \multicolumn{2}{|c|}{$\operatorname{Ly} \alpha$} & \multicolumn{2}{|c|}{$C$ IV $\lambda 1549^{b}$} & \multicolumn{2}{|c|}{$\begin{array}{c}\mathrm{C} \text { III] } \lambda 1909+ \\
\quad \mathrm{Si} \text { III] } \lambda 1892\end{array}$} & \multicolumn{2}{|c|}{$\mathrm{Mg}$ II $\lambda 2798$} \\
\hline & & $\begin{array}{r}\mathrm{F} \\
\mathrm{F} \\
\mathrm{FV} \\
\mathrm{FV} \\
\mathrm{FV} \\
\mathrm{A} \\
\mathrm{A}\end{array}$ & $\begin{array}{l}x \\
V \\
5 M \\
0 M \\
0 M \\
m \\
s\end{array}$ & $\begin{array}{r}\text { F } \\
1 \\
\mathrm{FV} \\
\mathrm{FV} \\
\mathrm{FV} \\
\mathrm{A}\end{array}$ & $\begin{array}{l}\mathrm{x} \\
\mathrm{V} \\
5 \mathrm{M} \\
0 \mathrm{M} \\
0 \mathrm{M} \\
\mathrm{m} \\
\mathrm{s}\end{array}$ & F & $\begin{array}{l}\mathrm{ux} \\
\mathrm{W} \\
50 \mathrm{M}\end{array}$ & $\begin{array}{r}\mathrm{Fl} \\
\mathrm{E} \\
\mathrm{FW}\end{array}$ & $\begin{array}{l}\mathrm{x} \\
\mathrm{M}\end{array}$ \\
\hline PKS 0112-01 & $\begin{array}{c}1.365 \\
1.0 \\
17.4 \\
0.20 \\
27.0 \\
1.42\end{array}$ & $\begin{array}{r}6.8 \\
39 \\
6503 \\
3781 \\
2424 \\
+0.01 \\
1\end{array}$ & $\begin{array}{l}\mathrm{g}(7.1) \\
(40) \\
\mathrm{cg} \\
\mathrm{cg} \\
\mathrm{bg} \\
\mathrm{cg}\end{array}$ & $\begin{array}{r}3.6 \\
24 \\
7995 \\
5189 \\
2783 \\
-0.06 \\
2\end{array}$ & $\begin{array}{l}\mathbf{a} \\
\mathbf{b} \\
\mathbf{b} \\
\mathbf{c} \\
\mathbf{c}\end{array}$ & $\begin{array}{r}2.7 \\
25 \\
7063\end{array}$ & $\begin{array}{l}\text { b } \\
\text { c }\end{array}$ & & \\
\hline $3 \mathrm{C} 47.0$ & $\begin{array}{c}0.425 \\
-1.0 \\
18.10 \\
0.17 \\
26.8 \\
0.76\end{array}$ & $\begin{array}{r}29.6 \\
196 \\
6520 \\
2713 \\
. \\
3\end{array}$ & $\begin{array}{l}\mathrm{g}(32.2) \\
(213) \\
\mathrm{bg} \\
\mathrm{bg}\end{array}$ & $\begin{array}{r}23.6 \\
210 \\
9555 \\
4273 \\
1870 \\
-0.13 \\
2\end{array}$ & $\begin{array}{l}\mathrm{g}(24.2) \\
(215) \\
\mathrm{bg} \\
\mathrm{bg} \\
\mathrm{cg} \\
\mathrm{dg}\end{array}$ & $\begin{array}{r}6.3 \\
72 \\
5324\end{array}$ & b & & \\
\hline PKS 0403-13 & $\begin{array}{c}0.571 \\
0.7 \\
17.09 \\
0.10 \\
26.9 \\
1.05\end{array}$ & $\begin{array}{r}30.8 \\
124 \\
4806 \\
2740 \\
1179 \\
+0.28 \\
3\end{array}$ & $\begin{array}{l}\mathbf{a} \\
\mathbf{a} \\
\mathbf{a} \\
\mathbf{a} \\
\mathbf{a}\end{array}$ & $\begin{array}{r}25.4 \\
138 \\
5709 \\
3366 \\
1533 \\
+0.26 \\
3\end{array}$ & $\begin{array}{l}\mathbf{a} \\
\mathbf{b} \\
\mathbf{a} \\
\mathbf{a} \\
\mathbf{a}\end{array}$ & $\begin{array}{r}4.4 \\
29 \\
\\
3317 \\
\\
\text { a }\end{array}$ & $\mathbf{b}$ & $\begin{array}{r}5.0 \\
43 \\
3715\end{array}$ & $\mathbf{a}$ \\
\hline $3 C 175$ & $\begin{array}{c}0.768 \\
-1.5 \\
16.60 \\
0.74 \\
27.5 \\
0.85\end{array}$ & $\begin{array}{r}109 \\
165 \\
14251 \\
5734 \\
2106 \\
-0.27 \\
3\end{array}$ & $\begin{array}{l}\mathrm{g}(113) \\
(170) \\
\mathrm{cg} \\
\mathrm{ag} \\
\mathrm{dg} \\
\mathrm{dg}\end{array}$ & $\begin{array}{r}34.2 \\
58 \\
15289 \\
7161 \\
2168 \\
-0.16 \\
1\end{array}$ & $\begin{array}{l}\mathbf{a} \\
\mathbf{c} \\
\mathbf{b} \\
\mathbf{c} \\
\mathrm{c}\end{array}$ & $\begin{array}{r}11.1 \\
25 \\
8400\end{array}$ & $\mathbf{b}$ & & \\
\hline $3 C 186$ & $\begin{array}{c}1.063 \\
<-1.4 \\
17.60 \\
0.17 \\
27.4 \\
0.95\end{array}$ & $\begin{array}{r}16.3 \\
117 \\
10165 \\
4005 \\
1164 \\
-0.02 \\
3\end{array}$ & $\begin{array}{l}\mathbf{b} \\
\mathbf{a} \\
\mathbf{b} \\
\mathrm{d} \\
\mathrm{d}\end{array}$ & $\begin{array}{r}8.6 \\
76 \\
11089 \\
5012 \\
\\
2\end{array}$ & $\begin{array}{l}\mathrm{g}(9.4) \\
(83) \\
\mathrm{cg} \\
\mathrm{dg}\end{array}$ & $\begin{array}{r}2.23 \\
24.4 \\
\\
5731\end{array}$ & $\mathbf{b}$ & & \\
\hline $3 C 207$ & $\begin{array}{c}0.684 \\
-0.5 \\
18.15 \\
0.21 \\
27.5 \\
1.83\end{array}$ & $\begin{array}{r}10.2 \\
106 \\
5112 \\
3218 \\
. \\
. \\
3\end{array}$ & $\begin{array}{l}\mathrm{g}(13.3) \\
(138) \\
\mathrm{cg} \\
\mathrm{dg}\end{array}$ & $\begin{array}{r}11.1 \\
114 \\
6760 \\
3803 \\
. \\
3\end{array}$ & $\begin{array}{l}\mathbf{g}(12.4) \\
(127) \\
\mathrm{cg} \\
\mathrm{dg}\end{array}$ & $\begin{array}{r}1.79 \\
20 \\
\\
3463\end{array}$ & $\mathbf{b}$ & $\begin{array}{r}2.0 \\
27 \\
\\
3149\end{array}$ & $\mathbf{b}$ \\
\hline PKS 0859-14 & $\begin{array}{c}1.327 \\
0.81 \\
16.59 \\
0.08 \\
27.5 \\
\ldots\end{array}$ & $\begin{array}{r}26.4 \\
80 \\
6838 \\
3938 \\
1855 \\
+0.05 \\
0\end{array}$ & $\begin{array}{l}\text { c } \\
\mathbf{a} \\
\mathbf{b} \\
\mathbf{b}\end{array}$ & $\begin{array}{l}\cdot \\
.\end{array}$ & & & & & \\
\hline
\end{tabular}


TABLE 2-Continued

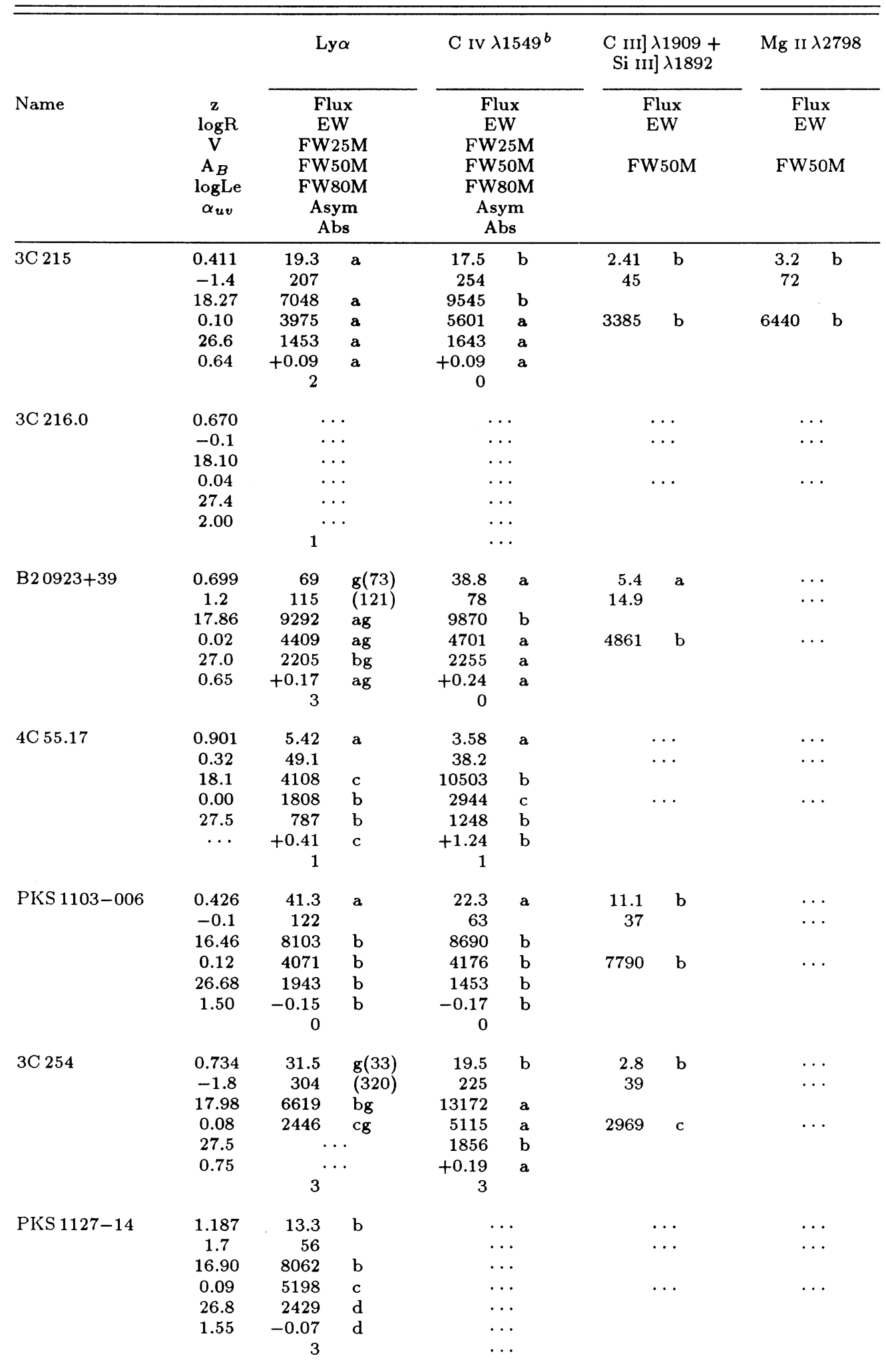


TABLE 2-Continued

\begin{tabular}{|c|c|c|c|c|c|c|c|c|c|}
\hline \multirow[b]{2}{*}{ Name } & \multirow[b]{2}{*}{$\begin{array}{c}\mathrm{z} \\
\log \mathrm{R} \\
\mathrm{V} \\
\mathrm{A}_{B} \\
\log \mathrm{Le} \\
\alpha_{u v}\end{array}$} & \multicolumn{2}{|c|}{$\operatorname{Ly} \alpha$} & \multicolumn{2}{|c|}{$\mathrm{C}$ IV $\lambda 1549^{b}$} & \multicolumn{2}{|c|}{$\begin{array}{c}\mathrm{C} \text { III] } \lambda 1909+ \\
\mathrm{Si} \text { III] } \lambda 1892\end{array}$} & \multicolumn{2}{|c|}{$\mathrm{Mg}$ II $\lambda 2798$} \\
\hline & & $\begin{array}{r}\mathrm{F} \\
\mathrm{F} \\
\mathrm{FW} \\
\mathrm{FW} \\
\mathrm{FY} \\
\mathrm{A}\end{array}$ & $\begin{array}{l}\mathbf{x} \\
V \\
5 \mathrm{M} \\
0 \mathrm{M} \\
0 \mathrm{M} \\
\mathrm{m} \\
\mathrm{s}\end{array}$ & $\begin{array}{r}\mathrm{F} \\
\mathrm{E} \\
\mathrm{FW} \\
\mathrm{FW} \\
\mathrm{FW} \\
\mathrm{A} \\
\mathrm{A}\end{array}$ & $\begin{array}{l}\mathbf{x} \\
v \\
5 \mathrm{M} \\
\mathrm{OM} \\
\mathrm{OM} \\
\mathrm{m} \\
\mathrm{s}\end{array}$ & $\begin{array}{r}\mathrm{F} \\
\mathrm{F} \\
\mathrm{FV}\end{array}$ & $\begin{array}{l}\mathrm{Nx} \\
N \\
\mathrm{NOM}\end{array}$ & $\begin{array}{r}\text { Fl } \\
\mathrm{E} \\
\text { FW }\end{array}$ & \\
\hline $3 C 263$ & $\begin{array}{c}0.652 \\
-1.1 \\
16.32 \\
0.01 \\
27.5 \\
0.77\end{array}$ & $\begin{array}{r}91.6 \\
114 \\
5571 \\
2742 \\
1280 \\
0.00 \\
1\end{array}$ & $\begin{array}{l}\mathbf{a} \\
\mathbf{a} \\
\mathbf{a} \\
\mathbf{a} \\
\mathbf{a}\end{array}$ & $\begin{array}{r}52.2 \\
86 \\
6261 \\
3362 \\
1622 \\
0.00 \\
1\end{array}$ & $\begin{array}{l}\mathbf{a} \\
\mathbf{a} \\
\mathbf{a} \\
\mathbf{a} \\
\mathbf{a}\end{array}$ & $\begin{array}{l}11.9 \\
25.3 \\
4567\end{array}$ & $\begin{array}{l}\text { b } \\
\text { c }\end{array}$ & $\begin{array}{r}11.5 \\
34 \\
4849\end{array}$ & $\begin{array}{l}\mathrm{b} \\
\mathrm{c}\end{array}$ \\
\hline $3 C 277.1$ & $\begin{array}{c}0.320 \\
-1.7 \\
17.93 \\
0.00 \\
26.8 \\
0.70\end{array}$ & & & $\begin{array}{r}21.8 \\
139 \\
6007 \\
2719 \\
1219 \\
+0.10 \\
3\end{array}$ & $\begin{array}{l}\mathrm{g}(22.5) \\
(143) \\
\mathrm{cg} \\
\mathrm{cg} \\
\mathrm{dg} \\
\mathrm{dg}\end{array}$ & $\begin{array}{r}3.5 \\
29 \\
\\
1922\end{array}$ & b & $\begin{array}{r}4.6 \\
55 \\
3091\end{array}$ & $\begin{array}{l}\mathbf{b} \\
\mathbf{b}\end{array}$ \\
\hline $3 \mathrm{C} 279$ & $\begin{array}{c}0.538 \\
1.1 \\
17.75 \\
0.06 \\
27.0 \\
2.07\end{array}$ & $\begin{array}{r}5.11 \\
29 \\
5048 \\
2385 \\
1295 \\
+0.15 \\
0\end{array}$ & $\begin{array}{l}\mathrm{b} \\
\mathrm{c} \\
\mathrm{b} \\
\mathrm{b} \\
\mathrm{b}\end{array}$ & $\begin{array}{r}5.42 \\
28.5 \\
12187 \\
5502 \\
1715 \\
+0.64 \\
0\end{array}$ & $\begin{array}{l}\mathbf{a} \\
\mathbf{b} \\
\mathrm{b} \\
\mathrm{c} \\
\mathrm{b}\end{array}$ & $\begin{array}{r}1.17 \\
6.1 \\
2769\end{array}$ & $\mathrm{c}$ & $\begin{array}{r}2.1 \\
11 \\
4037\end{array}$ & $c$ \\
\hline $3 C 288.1$ & $\begin{array}{c}0.961 \\
-2.2 \\
18.12 \\
0.01 \\
27.5 \\
1.00\end{array}$ & $\begin{array}{r}8.2 \\
56 \\
9472 \\
3916\end{array}$ & $\begin{array}{l}\mathrm{g}(8.8) \\
(60) \\
\mathrm{dg} \\
\mathrm{dg}\end{array}$ & $\begin{array}{r}5.2 \\
46 \\
10815 \\
5707\end{array}$ & $\begin{array}{l}\mathrm{g}(5.6) \\
(50) \\
\mathrm{d} \\
\mathrm{d}\end{array}$ & & . & & \\
\hline PKS 1354+19 & $\begin{array}{c}0.720 \\
0.37 \\
16.03 \\
0.06 \\
27.1 \\
1.25\end{array}$ & $\begin{array}{r}69.1 \\
183 \\
4222 \\
1909 \\
917 \\
+0.03 \\
1\end{array}$ & $\begin{array}{l}\mathbf{a} \\
\mathbf{a} \\
\mathbf{a} \\
\mathbf{a} \\
\mathbf{a}\end{array}$ & $\begin{array}{r}37.2 \\
108 \\
6557 \\
2860 \\
1308 \\
0.00 \\
0\end{array}$ & $\begin{array}{l}\mathbf{a} \\
\mathbf{a} \\
\mathbf{a} \\
\mathbf{a} \\
\mathbf{a}\end{array}$ & $\begin{array}{r}9.3 \\
32 \\
4134\end{array}$ & $\mathbf{b}$ & & \\
\hline $3 C 323.1$ & $\begin{array}{c}0.264 \\
-1.3 \\
16.69 \\
0.14 \\
26.5 \\
0.80\end{array}$ & $\begin{array}{r}176 \\
226 \\
7475 \\
3245 \\
1566 \\
-0.01 \\
3\end{array}$ & $\begin{array}{l}\mathrm{g}(187) \\
(241) \\
\mathrm{cg} \\
\mathrm{cg} \\
\mathrm{dg} \\
\mathrm{dg}\end{array}$ & $\begin{array}{r}102 \\
175 \\
10606 \\
4796 \\
1976 \\
0.00 \\
2\end{array}$ & $\begin{array}{l}\mathrm{b} \\
\mathrm{a} \\
\mathrm{a} \\
\mathrm{b} \\
\mathrm{a}\end{array}$ & $\begin{array}{r}16.5 \\
37 \\
\\
3616\end{array}$ & b & $\begin{array}{r}25 \\
74 \\
5315\end{array}$ & $\mathrm{~b}$ \\
\hline B2 1555+33 & $\begin{array}{c}0.942 \\
0.0 \\
18.3 \\
0.08 \\
26.5 \\
\ldots\end{array}$ & $\begin{array}{r}6.25 \\
122 \\
7418 \\
2962 \\
1068 \\
+0.34 \\
1\end{array}$ & $\begin{array}{l}\mathbf{a} \\
\mathrm{a} \\
\mathbf{a} \\
\mathrm{a} \\
\mathrm{a}\end{array}$ & $\begin{array}{r}5.08 \\
121 \\
8804 \\
3838 \\
1390 \\
+0.25 \\
2\end{array}$ & $\begin{array}{l}\mathbf{a} \\
\mathbf{a} \\
\mathrm{b} \\
\mathbf{a} \\
\mathbf{a}\end{array}$ & & . & & \\
\hline
\end{tabular}


TABLE 2-Continued

\begin{tabular}{|c|c|c|c|c|c|c|c|c|c|}
\hline \multirow[b]{2}{*}{ Name } & \multirow[b]{2}{*}{$\begin{array}{c}\mathrm{z} \\
\log \mathrm{R} \\
\mathrm{V} \\
\mathrm{A}_{B} \\
\log \mathrm{Le} \\
\alpha_{u v}\end{array}$} & \multicolumn{2}{|c|}{$\mathrm{Ly} \alpha$} & \multicolumn{2}{|c|}{$\mathrm{C}$ IV $\lambda 1549^{b}$} & \multicolumn{2}{|c|}{$\begin{array}{c}\mathrm{C} \text { III] } \lambda 1909+ \\
\quad \text { Si III] } \lambda 1892\end{array}$} & \multicolumn{2}{|c|}{$\mathrm{Mg}$ II $\lambda 2798$} \\
\hline & & $\begin{array}{r}F \\
\mathrm{E} \\
\mathrm{FW} \\
\mathrm{FW} \\
\mathrm{FW} \\
\mathrm{A} \\
\mathrm{A}\end{array}$ & $\begin{array}{l}\mathrm{x} \\
5 \mathrm{M} \\
\mathrm{OM} \\
\mathrm{OM} \\
\mathrm{m} \\
\mathrm{s}\end{array}$ & $\begin{array}{r}F \\
\mathrm{E} \\
\mathrm{FW} \\
\mathrm{FW} \\
\mathrm{FW} \\
\mathrm{A} \\
\mathrm{A}\end{array}$ & $\begin{array}{l}\mathrm{x} \\
\mathrm{M} \\
\mathrm{M} \\
\mathrm{m} \\
\mathrm{O}\end{array}$ & $\mathrm{FV}$ & $\begin{array}{l}\mathrm{Nx} \\
N\end{array}$ & $\begin{array}{r}\mathrm{Fl} \\
\mathrm{E} \\
\mathrm{FW}\end{array}$ & $\begin{array}{l}\mathbf{x} \\
\mathrm{OM}\end{array}$ \\
\hline DA 406 & $\begin{array}{c}1.401 \\
1.4 \\
17.5 \\
0.01 \\
27.0 \\
0.75\end{array}$ & $\begin{array}{r}12.5 \\
70 \\
6160 \\
2575 \\
. \\
3\end{array}$ & $\begin{array}{l}\mathrm{g}(13.0) \\
(73) \\
\mathrm{cg} \\
\mathrm{cg} \\
\end{array}$ & $\begin{array}{r}7.39 \\
47.9 \\
9678 \\
4774 \\
2566 \\
+0.37 \\
1\end{array}$ & $\begin{array}{l}\mathrm{g}(7.45) \\
(48.3) \\
\mathrm{cg} \\
\mathrm{cg} \\
\mathrm{dg} \\
\mathrm{dg}\end{array}$ & $\begin{array}{r}0.86 \\
7.5 \\
\\
5575\end{array}$ & $\mathbf{b}$ & & \\
\hline $3 C 334$ & $\begin{array}{c}0.555 \\
-0.7 \\
16.41 \\
0.14 \\
27.0 \\
0.85\end{array}$ & $\begin{array}{r}68.5 \\
121 \\
10476 \\
5218 \\
1499 \\
-0.16 \\
2\end{array}$ & $\begin{array}{l}a \\
b \\
b \\
d \\
c\end{array}$ & $\begin{array}{r}44.3 \\
99 \\
11983 \\
5063 \\
1933 \\
-0.07 \\
2\end{array}$ & $\begin{array}{l}\mathbf{a} \\
\mathbf{b} \\
\mathbf{a} \\
\mathbf{b} \\
\mathrm{b}\end{array}$ & $\begin{array}{l}11.0 \\
31.6 \\
7468\end{array}$ & $\mathbf{b}$ & $\begin{array}{r}12.8 \\
56 \\
5224\end{array}$ & b \\
\hline OS 562 & $\begin{array}{c}0.750 \\
0.6 \\
17.0 \\
0.00 \\
27.4 \\
0.92\end{array}$ & $\begin{array}{r}34.8 \\
90 \\
5655 \\
2762 \\
1164 \\
-0.03 \\
0\end{array}$ & $\begin{array}{l}\mathbf{a} \\
\\
\mathbf{a} \\
\mathbf{a} \\
\mathbf{a} \\
\mathbf{a}\end{array}$ & $\begin{array}{r}17.1 \\
54.8 \\
7869 \\
3671 \\
1655 \\
+0.16 \\
1\end{array}$ & $\begin{array}{l}\mathbf{a} \\
\mathbf{a} \\
\mathbf{b} \\
\mathrm{b} \\
\mathbf{b}\end{array}$ & $\begin{array}{r}4.7 \\
20 \\
5013\end{array}$ & $\mathbf{b}$ & & \\
\hline $3 \mathrm{C} 345$ & $\begin{array}{c}0.594 \\
1.5 \\
15.96 \\
0.00 \\
26.6 \\
1.58\end{array}$ & $\begin{array}{r}35 \\
97 \\
7625 \\
3803 \\
1798 \\
+0.18 \\
3\end{array}$ & $\begin{array}{l}\mathbf{b} \\
\mathbf{b} \\
\mathbf{b} \\
\mathbf{b} \\
\mathbf{b}\end{array}$ & $\begin{array}{r}30.4 \\
87 \\
8922 \\
4829 \\
2100 \\
+0.22 \\
1\end{array}$ & $\begin{array}{l}\mathbf{a} \\
\mathbf{b} \\
\mathbf{a} \\
\mathbf{a} \\
\mathbf{a}\end{array}$ & $\begin{array}{r}6.5 \\
19.6 \\
4098\end{array}$ & c & $\begin{array}{r}6.7 \\
24 \\
4196\end{array}$ & b \\
\hline $\mathrm{B} 22201+31 \mathrm{~A}$ & $\begin{array}{c}0.297 \\
0.2 \\
15.58 \\
0.48 \\
26.6 \\
1.00\end{array}$ & $\begin{array}{r}254 \\
72 \\
11938 \\
4394 \\
2076 \\
-0.01 \\
1\end{array}$ & $\begin{array}{l}\mathbf{b} \\
\mathbf{b} \\
\mathbf{a} \\
\mathbf{a} \\
\mathbf{b}\end{array}$ & $\begin{array}{r}147 \\
50.4 \\
11827 \\
5281 \\
2466 \\
+0.07 \\
1\end{array}$ & $\begin{array}{l}\mathbf{a} \\
\\
\mathbf{a} \\
\mathbf{a} \\
\mathbf{a} \\
\mathbf{a}\end{array}$ & $\begin{array}{r}62 \\
28 \\
7184\end{array}$ & $\mathbf{b}$ & $\begin{array}{r}45 \\
35 \\
4394\end{array}$ & $\begin{array}{l}\mathbf{b} \\
\mathbf{b}\end{array}$ \\
\hline PKS 2216-038 & $\begin{array}{c}0.901 \\
1.1 \\
16.38 \\
0.20 \\
26.7 \\
\ldots\end{array}$ & $\begin{array}{r}30.0 \\
110 \\
7006 \\
2979 \\
912 \\
+0.02 \\
1\end{array}$ & $\begin{array}{l}\mathbf{a} \\
\mathbf{a} \\
\mathbf{a} \\
\mathbf{a} \\
\mathbf{a}\end{array}$ & $\begin{array}{r}18.0 \\
68 \\
10321 \\
3714 \\
1366 \\
+0.19 \\
0\end{array}$ & $\begin{array}{l}\mathbf{a} \\
\mathbf{a} \\
\mathbf{b} \\
\mathbf{a} \\
\mathbf{b}\end{array}$ & $\begin{array}{r}4.6 \\
19 \\
6012\end{array}$ & $\mathbf{b}$ & & \\
\hline $3 C 446$ & $\begin{array}{c}1.404 \\
1.5 \\
18.39 \\
0.20 \\
27.2 \\
1.83\end{array}$ & $\begin{array}{r}6.86 \\
109 \\
5006 \\
2510 \\
1125 \\
-0.06 \\
0\end{array}$ & $\begin{array}{l}\mathbf{a} \\
\mathbf{a} \\
\mathbf{a} \\
\mathbf{a} \\
\mathbf{a}\end{array}$ & $\begin{array}{r}5.1 \\
75 \\
7581 \\
3449 \\
1496 \\
+0.10 \\
0\end{array}$ & $\begin{array}{l}\mathbf{b} \\
\mathrm{b} \\
\mathrm{b} \\
\mathrm{b} \\
\mathrm{b}\end{array}$ & $\begin{array}{r}0.92 \\
15 \\
4418\end{array}$ & $\mathrm{~d}$ & & \\
\hline
\end{tabular}


TABLE 2-Continued

\begin{tabular}{|c|c|c|c|c|c|c|c|c|c|}
\hline \multirow[b]{2}{*}{ Name } & \multirow[b]{2}{*}{$\begin{array}{c}\mathrm{z} \\
\log \mathrm{R} \\
\mathrm{V} \\
\mathrm{A}_{B} \\
\log \mathrm{Le} \\
\alpha_{u v}\end{array}$} & \multicolumn{2}{|c|}{$\mathrm{Ly} \alpha$} & \multicolumn{2}{|c|}{$\mathrm{C}$ IV $\lambda 1549^{b}$} & \multicolumn{2}{|c|}{$\begin{array}{c}\mathrm{C} \text { III] } \lambda 1909+ \\
\mathrm{Si} \text { III] } \lambda 1892\end{array}$} & \multicolumn{2}{|c|}{$\operatorname{Mg}$ II $\lambda 2798$} \\
\hline & & $\begin{array}{r}\mathrm{F} \\
\mathrm{E} \\
\mathrm{FW} \\
\mathrm{FW} \\
\mathrm{FY} \\
\mathrm{A}\end{array}$ & $\begin{array}{l}\mathbf{x} \\
5 \mathrm{M} \\
\mathrm{OM} \\
\mathrm{OM} \\
\mathrm{m} \\
\mathrm{s}\end{array}$ & $\begin{array}{r}\mathrm{F} \\
\mathrm{F} \\
\mathrm{FV} \\
\mathrm{FY} \\
\mathrm{FV} \\
\mathrm{A}\end{array}$ & $\begin{array}{l}x \\
5 \mathrm{M} \\
\mathrm{OM} \\
\mathrm{OM} \\
\mathrm{m}\end{array}$ & & $\begin{array}{l}\mathrm{Nx} \\
N \\
\mathrm{OM}\end{array}$ & $\begin{array}{r}\text { Fl } \\
\text { E } \\
\text { FW }\end{array}$ & $\begin{array}{l}\mathbf{x} \\
\mathrm{OM}\end{array}$ \\
\hline CTA 102 & $\begin{array}{c}1.037 \\
1.4 \\
17.33 \\
0.17 \\
26.9 \\
0.88\end{array}$ & $\begin{array}{r}26.7 \\
79 \\
5563 \\
3083 \\
1593 \\
+0.09 \\
1\end{array}$ & $\begin{array}{l}a \\
b \\
a \\
a \\
b\end{array}$ & $\begin{array}{r}13.2 \\
45 \\
6632 \\
3340 \\
1661 \\
+0.13 \\
1\end{array}$ & $\begin{array}{l}a \\
b \\
a \\
a \\
b\end{array}$ & $\begin{array}{r}3.6 \\
16 \\
3903\end{array}$ & b & & \\
\hline $3 C 454.3$ & $\begin{array}{c}0.859 \\
1.2 \\
16.10 \\
0.26 \\
27.4 \\
1.52\end{array}$ & $\begin{array}{r}26.7 \\
74 \\
4937 \\
2804 \\
1364 \\
-0.04 \\
0\end{array}$ & $\begin{array}{l}\mathbf{a} \\
\\
\mathbf{a} \\
\mathbf{a} \\
\mathbf{a} \\
\mathbf{a}\end{array}$ & $\begin{array}{r}14.4 \\
41 \\
5254 \\
3145 \\
1496 \\
0.00 \\
2\end{array}$ & $\begin{array}{l}\mathrm{b} \\
\mathrm{a} \\
\mathrm{a} \\
\mathrm{b} \\
\mathrm{a}\end{array}$ & $\begin{array}{r}6.2 \\
20 \\
5175\end{array}$ & $\mathrm{~b}$ & & \\
\hline PKS $2251+11$ & $\begin{array}{c}0.323 \\
-1.5 \\
15.82 \\
0.15 \\
26.5 \\
1.10\end{array}$ & $\begin{array}{r}95 \\
136 \\
5692 \\
2930\end{array}$ & $\begin{array}{l}\mathrm{g}(105) \\
(149) \\
\mathrm{cg} \\
\mathrm{dg}\end{array}$ & $\begin{array}{r}63 \\
117 \\
7567 \\
3758\end{array}$ & $\begin{array}{l}\mathrm{g}(69) \\
(128) \\
\mathrm{cg} \\
\mathrm{cg}\end{array}$ & $\begin{array}{r}22 \\
49 \\
5423\end{array}$ & b & $\begin{array}{r}19 \\
38 \\
4598\end{array}$ & $\mathrm{~b}$ \\
\hline
\end{tabular}

a Entries of second column: $z$, redshift; $\log R$, radio core dominance parameter; $V, V$ magnitude; $A_{B}$, Galactic extinction in $B$ band; $\log L_{e}$, radio lobe luminosity; $\alpha_{u v}$, UV spectral index $\left(F_{v} \sim v^{-\alpha_{U v}}\right)$.

Line parameters: flux, observed frame integrated flux $\left(10^{-14} \mathrm{ergs} \mathrm{s}^{-1} \mathrm{~cm}^{-1}\right) ; \mathrm{EW}$, rest frame equivalent width $(\AA)$; FW25M, full width $(c \Delta \lambda / \lambda)$ at $25 \%$ of line peak $\left(\mathrm{km} \mathrm{s}^{-1}\right)$. Asym, asymmetry parameter at $25 \%$ of line peak $(0$, a symmetric line; positive, strong long-wavelength wing). Abs, a flag indicating the strength of associated absorption ( 0 , no absorption seen; 3 , strong absorption). Line width and asymmetry measurements are of the observed profiles, with no attempt to correct for the fact that the line may be an atomic multiplet.

${ }^{b} \mathrm{C}$ IV measurements include the $\sim \lambda 1600$ emission feature.

\subsection{Absolute Flux Density Scale}

The flux density calibration is important for our science because quasars are variable, and we need to combine these ultraviolet data with quasi-simultaneous ground-based data obtained at longer wavelengths.

The absolute flux density calibration was performed using the inverse sensitivity calibration files derived by STScI staff for each grating setting, using observations of the spectrophotometric standard stars, $\mathrm{HZ} 44, \mathrm{BD}+28^{\circ} 4211$, and $\mathrm{BD}+75^{\circ} 325$ through the $4^{\prime \prime} 3$ aperture, between 1991.4 and 1992.2 (Neill, Bohlin, \& Hartig 1992; Taylor \& Keyes 1993). The external flux density scale is thought to be accurate to from $10 \%$ to $5 \%$ over the range from 1300 to $3200 \AA$. The internal consistency of the scale is better than $5 \%$ (Bohlin \& Neill 1992). With centering accuracy within $\sim 0$.'1, we expect uncertainties resulting from light losses to be negligible. However, the sensitivity for the blue $\mathrm{G130H}$ observations was decreasing by about $10 \%$ per year at all wavelengths, while the sensitivity of the red Digicon is constant within $\sim 5 \%$, except between 1800 and $2100 \AA$, where it was also declining by about $10 \%$ per year. In addition the PSF of $H S T$ 's aberrated image, and hence the aperture throughput, depends on HST's focus, which changes (in a known way) with time (Lindler $\&$ Bohlin
1993). Pointing and tracking errors caused by GIM, solar array glitches, and perhaps an electronic drift of the spectrum in the direction perpendicular to dispersion, combined with the PSF and varying sensitivity (which may in fact be related to the focus changes and electronic drift), limit our present calibration accuracy to 5\%-10\% (Bohlin 1993; Koratkar \& Taylor 1993; Evans 1993)-but with some hope of improved recalibration of these observations in the future.

As an internal check of the FOS flux calibration, we found that the flux densities in the regions of overlap between different gratings, $30-80 \AA$, agreed to within the rms uncertainties of $\sim 8 \%$. This is an upper limit as this comparison is least accurate at the ends of the arrays; the sensitivity is lower there for some configurations, and the electronic image is tilted and S-distorted at the diode array so the ends are most affected.

As a further check, we have compared our spectra with those observed by Bahcall et al. (1993) for four of our quasars in common. Bahcall et al. (1993) used the FOS with the 1".0 diameter aperture. We find that the continuum flux ratios of Bahcall et al.'s spectra to ours are 0.99 for PKS 2251+113 (observations within 7 weeks), 1.08 for PKS 1354+195 (for which Bahcall et al.'s observations were made 14 months earlier and used the low-resolution G160L grating), 1.12 for 3C 263 (5 weeks apart), and 1.58 for 3C 454.3 (observations 
separated by 2 months). The large ratio for $3 \mathrm{C} 454.3$ reflects real continuum time variability; the emission-line strengths remained constant to within $\sim 5 \%$. Thus the spectra agree within the expected calibration uncertainty for the smaller aperture observations for which centering may contribute as much as a $20 \%$ error.

\subsection{Correction for Dead Diodes and Noise Spikes}

Except at the end of the spectrum, five diodes normally contribute to the flux density measurement at each wavelength. If a diode is known to be noisy or "dead" it can be disabled before data acquisition, and the count rates corrected on-line. In this case the flux density is nearly always recovered as it will generally be measured by four other diodes. Occasionally a single diode is dead and not recognized as such before the observation; conversely, a diode may be mistakenly flagged as dead. This affects 20 pixels, and their measured fluxes must be multiplied by $5 / 4$ or, conversely, $4 / 5$. A single, unrecognized, noisy diode would corrupt 20 pixels in the output spectrum. We noticed only two such problems that affected the line fitting. One was on the red side of Ly $\alpha$ of PKS 0112-01. The data were sufficiently noisy that the affected wavelength interval was excluded from subsequent analysis. The other was on the red wing of $\mathrm{C}$ IV for $3 \mathrm{C} 254$; the affected region was also excluded. The interval very nearly coincided with the interval [1590 $\AA, 1620 \AA]$ which was excluded from all the fits anyway (see $\S 5.1$ ).

A few times in our whole data set, we noticed spikes affecting individual pixels, fortunately never near emission lines.

\subsection{Combining the Spectra, Galactic Extinction}

All the data for a given object were averaged in 3 pixel blocks. Each new combined point had wavelength and flux values from the $1 / \sigma^{2}$ weighted average of the contributing data values. (The overlap regions used the 3 pixel intervals defined by the red or blue spectrum, depending on which half of the overlap the wavelength in question fell, but all data in any given interval were used.) The combined spectra were corrected for Galactic extinction using the empirical function derived by Cardelli, Clayton, \& Mathis (1989, in IRAF) with $R=3.2$ and the $E_{\mathrm{B}-\mathrm{v}}$ values as given by Burstein \& Heiles (1982).

The combined spectra are shown in Figure 2, separated into four groups (Figs. $2 a-2 d$ ) according to ultraviolet spectral index, from $\alpha_{U v}=0.5$ to 1.9 , i.e., $F_{v} \propto v^{-\alpha U v}$ or, in terms of $F_{\lambda}$ used in Figure 2, $F_{\lambda} \propto \lambda^{\alpha u v-2}$. The most prominent emission lines are indicated: $\operatorname{Ly} \alpha, C_{\text {IV }} \lambda 1549, \mathrm{C}$ III] $\lambda 1909$, and $\mathrm{Mg}$ II 22798. Note that all spectra are plotted on the same logarithmic flux density scale, so that line to continuum ratios can be directly compared. Further details are given in the figure caption.

\section{MEASUREMENT OF CONTINUUM AND EMISSION LINES}

Our aim here is to present first-order characteristics of the spectra-an ultraviolet spectral index, and line measurements: fluxes, equivalent widths, various line widths, and asymmetries for the prominent lines of Ly $\alpha, \mathrm{C}$ IV $\lambda 1549, \mathrm{C}$ III] $\lambda 1909, \mathrm{Mg}$ II 22798, and relative line strengths for these lines and weaker features. The largest uncertainties in determining the continuum shape arise from the lack of entirely line-free wavelength regions and, for the lower redshift quasars at lowest Galactic latitudes, uncertainties in the correction for Galactic extinction. For emission-line measurements, even for the leastblended line, $\mathrm{C}$ IV $\lambda 1549$, the greatest uncertainties are usually in determining the true continuum level and in deblending the emission from weaker lines. For a few quasars, strong associated absorption in $\mathrm{Ly} \alpha$ and $\mathrm{C}$ IV introduces significant uncertainty. In future papers, a combination of techniques, including spectral principal component analyses (e.g., Francis et al. 1992), will more fully explore the potential information in the complete data set, such as detailed differences between profiles of different lines.

The ultraviolet spectral indices $F_{v} \propto v^{-\alpha u v}$ (Table 2, col. [2]) were determined from power laws fitted visually through the lowest continuum points near 1150, 1450, 1700, and $2050 \AA$, where available, taking into account the noise, and to a lesser extent, for a few quasars at the shorter wavelengths, uncertainties in Galactic extinction. For spectra with very broad lines, it is likely that none of these wavelength regions represents the true continuum; this was especially obvious near $1450 \AA$. Despite the uncertainties, this spectral index is well defined for most spectra.

Although we used Gaussian component fitting to deblend the regions of $\mathrm{Ly} \alpha, \mathrm{C}$ IV, and $\mathrm{C} I \mathrm{II}]$, profile measurements for these strong lines were made directly from the continuum- and blend-subtracted data to minimize their dependence on the appropriateness of the analytical fits. For the deblending, and for the flux measurements of weaker lines, we represented the profiles by two (or three) Gaussian components, with stronger constraints for weaker lines-the two- or three-Gaussian composite $\mathrm{C}$ IV profile was fitted to the weakest lines. Below we describe the procedure and present the results.

\subsection{Line Fitting and Deblending} form

We subtracted from the total spectrum a continuum of the

$$
F_{\lambda} \propto\left(\frac{\lambda}{\lambda_{0}}\right)^{\left[a_{0}+a_{1}\left(\lambda / \lambda_{0}\right)\right]},
$$

where $\lambda_{0}=1549 \AA$. Each profile was then represented by two (or three) Gaussian components, where the relative shifts from the nominal line center and the FWHM of each component were fixed at the same values for all lines. The parameters were determined by hand using $C$ IV and Ly $\alpha$ with consideration for $\mathrm{N} v$ and the other lines in the wings of the stronger features. We then fitted the amplitudes only, for all components and for all lines, by a simultaneous linear least-squares method.

Next we reran the least squares fit to all lines, with the same relative velocity shifts and velocity widths for the components, but with the following constraints. For the strong lines, the two (or three) amplitudes were unconstrained. For $N$ v $\lambda 1240$ and C III] $\lambda 1909$, either two amplitudes were unconstrained, or, when three components were used, the ratio of the amplitudes of the two broadest was fixed at the $\mathrm{C}$ IV value. For the remaining (weak) features (see Table 3) we fixed the relative amplitudes of all two or three Gaussian components at the values previously found for C IV.

Several details should be mentioned. First, in cases of atomic multiplets with significant member separation, each member of the multiplet included the two (or three) Gaussian components, with flux ratios among members determined by the ratios of atomic levels' statistical weights. Also the $\mathrm{O}$ I $\lambda 1303$ triplet and the $\mathrm{Si}$ II $\lambda 1307$ doublet were assumed to contribute equal flux to the blend. Similarly, the flux of the Si IV $\lambda 1397$ doublet was set equal to that of the $O \mathrm{IV}] \lambda 1402$ multiplet. These weights are summarized in Table 4. 


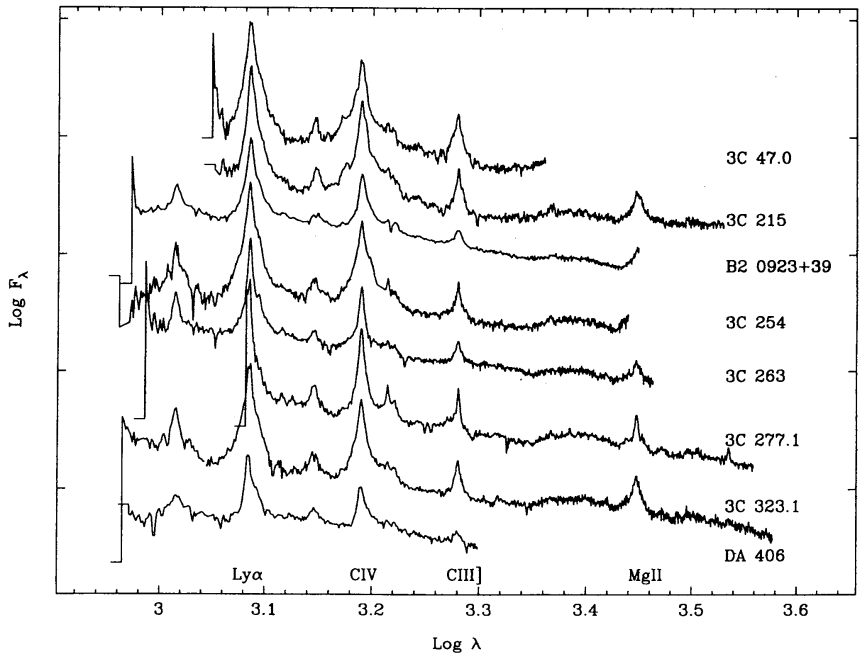

FIG. $2 a$

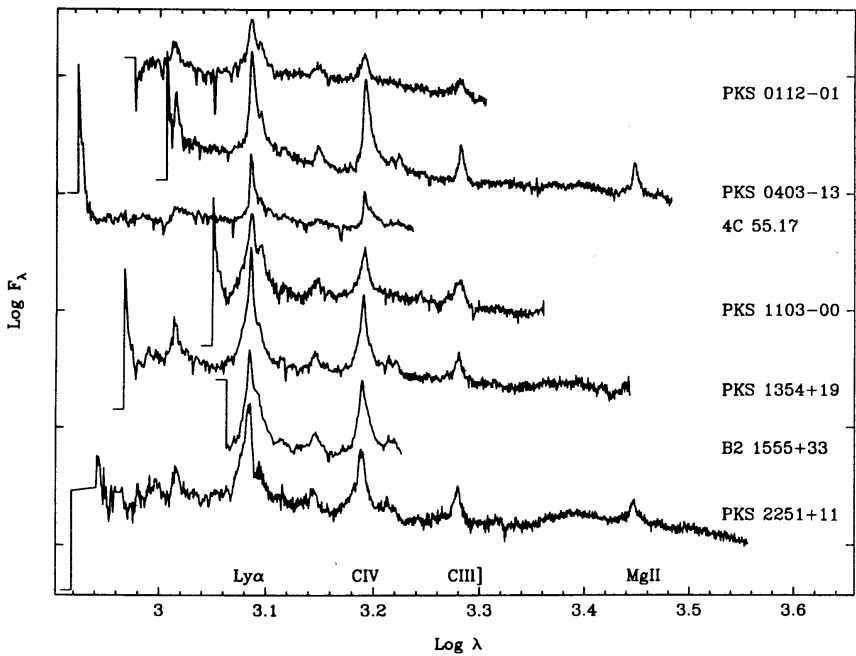

Fig. $2 c$

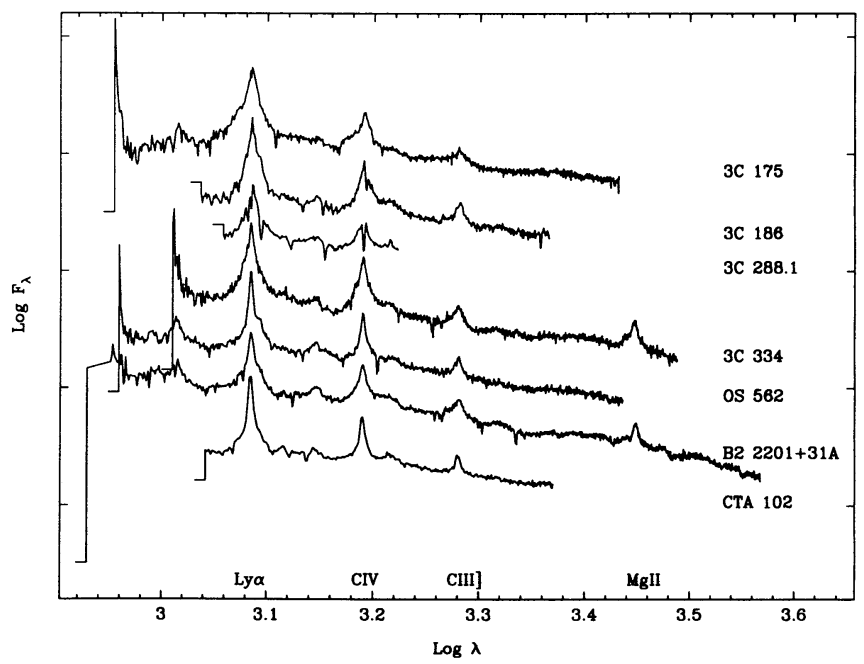

Fig. $2 b$

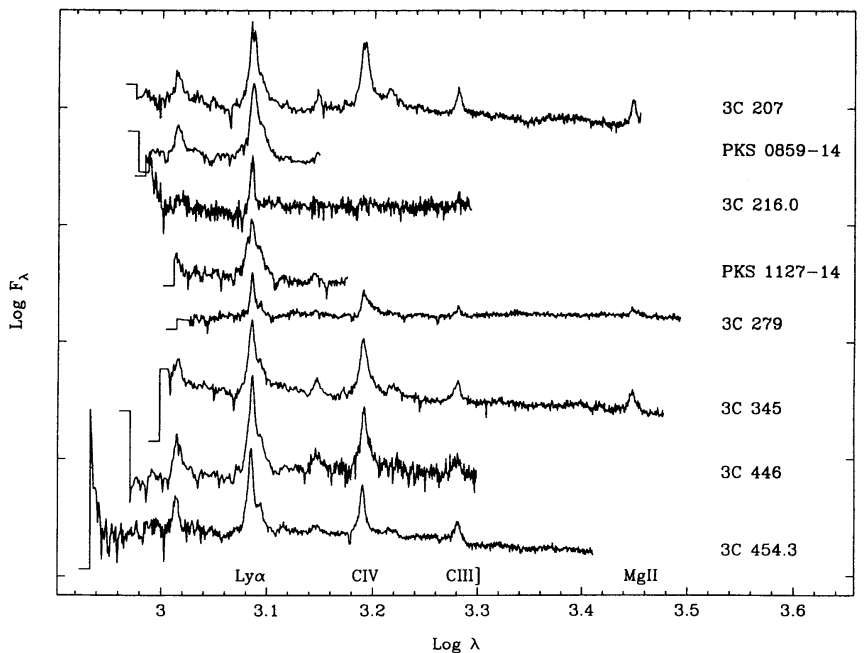

Fig. $2 d$

FIG. 2.-Spectra of radio-loud quasars observed with the Faint Object Spectrograph of the Hubble Space Telescope. Observed flux density $\left(F_{2}\right)$ is plotted vs. rest wavelength. All spectra are corrected for reddening within our Galaxy. They are shown in four panels, $(a)-(d)$, according to ultraviolet spectral index, from flattest $\left(F_{v} \propto v^{-0.5}\right)$ to steepest $\left(F_{v} \propto v^{-1.9}\right)$. Within each panel the quasars are represented in order of right ascension; $(c)$ and $(d)$ include only the most variable, core-dominant quasars. The scales in $\log F_{\lambda}$ are the same in each panel, so that line-to-continuum ratios may be compared directly, but the scales are displaced for display purposes. The bars connected to the short-wavelength ends of the spectra represent observed flux densities of $10^{-15} \mathrm{ergs} \mathrm{s}^{-1} \mathrm{~cm}^{-2} \AA^{-1}$. For display purposes the data are shown binned by eight (original) pixels for the G130H data (the resolution in the original spectrum is about six original pixels), and approximately equivalent to the wavelength resolution for the $\mathrm{G} 190 \mathrm{H}-\mathrm{G} 400 \mathrm{H}$ spectra. The most prominent emission lines are indicated: Ly $\alpha \lambda 1216, \mathrm{C}$ IV $\lambda 1549, \mathrm{C}$ III] $\lambda 1909$, and $\operatorname{Mg}$ II 22798 .

Second, in the region of $1600 \AA$, the effect of excess emission attributed to $\mathrm{Fe}$ II and possibly other species (Laor et al. 1994; Netzer \& Wills 1983; Wills, Netzer, \& Wills 1980) was reduced by removing the interval between 1580 and $1610 \AA$ from the fit. Similarly, for the $\lambda 1909$ feature, we removed the region beyond $1950 \AA$.

Third, there were several regions where the estimated continuum did not always match the data very well, so a local continuum was defined and the affected lines refitted. The Balmer continuum, $\mathrm{Fe}$ II, and possibly other blended emission form a quasi-continuum near $\mathrm{C}$ III] $\lambda 1909$, and especially in the region of Mg II. Only integrated flux and FWHM (=FW50M) were measured for the $\mathrm{Mg}$ II and C III] 21909 lines. Because of the uncertain continuum extrapolation and the generally poor signal-to-noise ratio at wavelengths below Ly $\alpha$ (see Fig. 2), here we have redefined a local continuum and fitted the $\mathrm{C}$ IV template by hand at the nominal wavelengths of C III $2977, \mathrm{~N}$ III] $\lambda 991, \operatorname{Ly} \beta$, and $O$ VI $\lambda 1034$.

Lastly, we note that the linear least-squares algorithm included a loop that prevented negative values for line component fluxes. Although our procedure produced a satisfactory set of fitted values, in the presence of zero-valued components the fit is technically nonlinear. In these cases the uncertainties and the upper limits derived from the fit are still useful, although approximate. Anyway, uncertainties in the continuum level dominate.

\subsection{Line Measurements: Results}

Measurements of the Ly $\alpha, C_{\text {IV }}, \mathrm{C}$ III], and $\mathrm{Mg}$ II profiles are given in Table 2, and details of the profiles and fitted blends are 


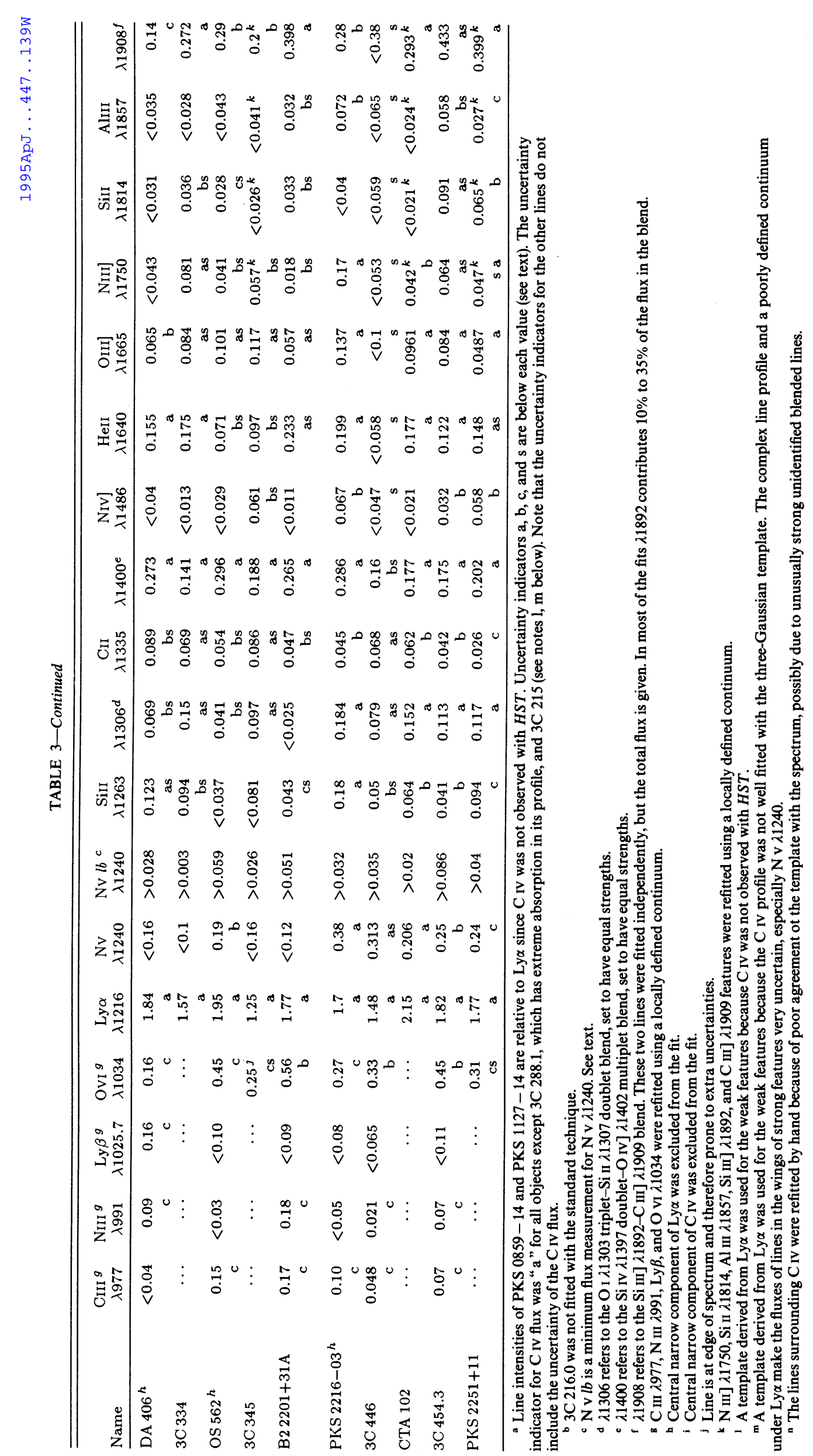


TABLE 4

Weights for Components of Emission Features

\begin{tabular}{|c|c|c|c|c|c|c|}
\hline$\lambda_{e f f}(\AA)$ & Species & $\lambda_{v a c}$ (weight) $\ldots$ & & & & \\
\hline 1240 & N V & $1238.81(0.67)$ & $1242.80(0.33)$ & & & \\
\hline $1263^{a}$ & Si II & $1260.42(0.33)$ & $1264.74(0.60)$ & $1265.00(0.07)$ & & \\
\hline $1306^{b}$ & Si II & $1304.37(0.33)$ & $1309.27(0.67)$ & & & \\
\hline 1335 & $\mathrm{C} \mathrm{II}$ & $1334.53(0.33)$ & $1335.66(0.07)$ & $1335.71(0.60)$ & & \\
\hline $1400^{\mathrm{b}}$ & Si IV & $1393.76(0.67)$ & $1402.77(0.33)$ & & & \\
\hline $1664^{\mathrm{a}}$ & O III] & $1660.80(0.29)$ & $1666.14(0.71)$ & & & \\
\hline 1750 & N III]c & $1748.65(0.21)$ & $1749.67(0.48)$ & $1752.16(0.08)$ & $1754.00(0.23)$ & \\
\hline 1814 & Si II & $1808.01(0.33)$ & $1816.93(0.60)$ & $1817.45(0.07)$ & & \\
\hline 1860 & Al III & $1854.72(0.67)$ & $1862.79(0.33)$ & & & \\
\hline
\end{tabular}

a These features are likely to be blended with $\mathrm{Fe}$ II.

b The two species were assumed to contribute equally.

c The values used were slightly different from those presented here.

shown in Figure 3. For all four lines we give integrated flux, equivalent width, and FW50M values. In addition, for the Ly $\alpha$ and $\mathrm{C}$ IV profiles we give measures of full width at $25 \%$ and $80 \%$ of the peak amplitude (FW25M and FW80M), and an asymmetry parameter

$$
\text { Asym } \equiv \frac{\lambda_{25}-\lambda_{80}}{\text { FW50M }}
$$

where $\lambda_{25}$ and $\lambda_{80}$ are the central wavelengths measured at the $25 \%$ and $80 \%$ levels. The Ly $\alpha$ and $C$ IV lines also have an estimated index of associated absorption $(0=$ no absorption visible, 3 = strong).

As described above, the Ly $\alpha$ measurements exclude contributions from $\mathrm{N} \mathrm{v}$ and weaker blends at longer wavelengths. The $\mathrm{C}$ IV measurements exclude contributions from $\mathrm{N}$ IV] $\lambda 1486, \mathrm{He}$ II $\lambda 1640$, and $\mathrm{O}$ III] $\lambda 1663$, but, as there is no reliable way to separate the $\mathrm{C}$ IV long-wavelength wing from the excess emission sometimes seen between $\mathrm{C}$ IV and the $\mathrm{He}$ II-O III] blend, this is included in the C IV measurements. Fitted components of Si II $\lambda 1814$ and Al III $\lambda 1857$ were removed if they significantly affected the C III] $\lambda 1909$ profile, but we could not distinguish the Si III $\lambda 1892$ feature well enough to remove it.

Measurement uncertainties are denoted by $a, b$, or c, referring to $\leq 10 \%, 10 \%-20 \%$, and $20 \%-33 \%$, respectively. In addition, $d$ refers to problems with profile shape measurements, such as where strong absorption required uncertain interpolation. In cases where the line peak was very uncertain because of apparent absorption, we have listed two flux (and EW) values. The first measurement of line strength is made by interpolating linearly across the absorption, and so is an estimate of a lower limit on the flux; the second (in parentheses) is derived from an estimate of the unabsorbed profile shape. Where widths and Asym depend on an estimate of the unabsorbed profile shape, we note this by a " $\mathrm{g}$."

Table 3 shows the intensities of all lines, relative to C IV, determined from the $\mathrm{C}$ IV template fit as described in $\S 5.1$. For Ly $\alpha, C_{\text {IV }}$, and the C III] $\lambda 1909-\mathrm{Si}$ III $\lambda 1892$ blend the fluxes of Table 2 are preferred, as the profiles of these stronger lines often deviate significantly from the three-Gaussian component template for $\mathrm{C}$ IV. The $\mathrm{a}, \mathrm{b}$, and $\mathrm{c}$ represent uncertainties as for Table 2. These do not include systematic uncertainties arising from absorption lines or continuum placement, which are often dominant for the weaker lines, and may correlate from line to line. The continuum placement is especially uncertain where weak lines occur in the wings of the strong lines, such as $\mathrm{Si}$ II $\lambda 1260$ in the wing of the Ly $\alpha-\mathrm{N} v \lambda 1240$ blend, or $N$ IV] $\lambda 1486$ in the wing of $\mathrm{C}$ IV $\lambda 1549$. The "s" represents such an unquantifiable source of systematic error in particularly problematic cases. We have not included uncertainties resulting from unidentified weak blends. In particular, $\mathrm{Fe}$ II emission blends are expected to contribute significantly near $1260 \AA$ and in the He II $\lambda 1640-\mathrm{O}$ III] $\lambda 1663$ region. Ly $\gamma$ at $972 \AA$ may contribute to $\mathrm{C}_{\text {III }} \lambda 977$.

Because of the importance of $\mathrm{N} \mathrm{V}$ in studies of the BLR abundances (Hamann \& Ferland 1993) and the sensitivity of the measured $\mathrm{N} v$ flux to the chosen Gaussian parameters for Ly $\alpha$, we estimated lower limits to its flux by integrating the spectrum above an interpolated smooth wing of $L y \alpha$, in the region of $\lambda_{\text {rest }} \sim 1240 \AA$. These values are shown in Table 3 , in the column marked " $\mathrm{N} v \mathrm{lb}$." If there is no significant bump, we have given 0.0 as the lower limit.

\section{DISCUSSION}

Although the 31 ultraviolet spectra presented here will be discussed in much more detail when we present the combined ultraviolet, optical, and infrared spectroscopy, we are able to make some unique observations here because this paper adds very significantly to the few good signal-to-noise ratio and good resolution $\left(\sim 350 \mathrm{~km} \mathrm{~s}^{-1}\right)$ ultraviolet spectra that are available for low- and intermediate-redshift quasars.

The strengths of lines below $L y \alpha$ are difficult to measure in quasars observed from the ground because, at high redshifts, this region of the spectrum is confused by Ly $\alpha$ forest absorption by intergalactic clouds. The emission lines predicted to be strongest here are $\operatorname{Ly} \beta$ at $1025 \AA, C$ III $\lambda 977, O$ vi $\lambda \lambda 1032,1038$, and $\mathrm{N}$ III $\lambda \lambda 990,992$, but there are a number of other lines that may contribute-O I at 972, 974, 988, and $1026 \AA, F e$ II emission, and perhaps Si II. The O VI $\lambda 1034 / \mathrm{Ly} \alpha$ line ratio is a good measure of the ionization parameter. The C III $\lambda 977$ line is very important in determining the density of the BLR gas. In particular, it is predicted to be strong at very high densities $\left(\geq 10^{11}\right.$ $\mathrm{cm}^{-3}$ ) when the other important cooling agents (C IV $\lambda 1549$, 

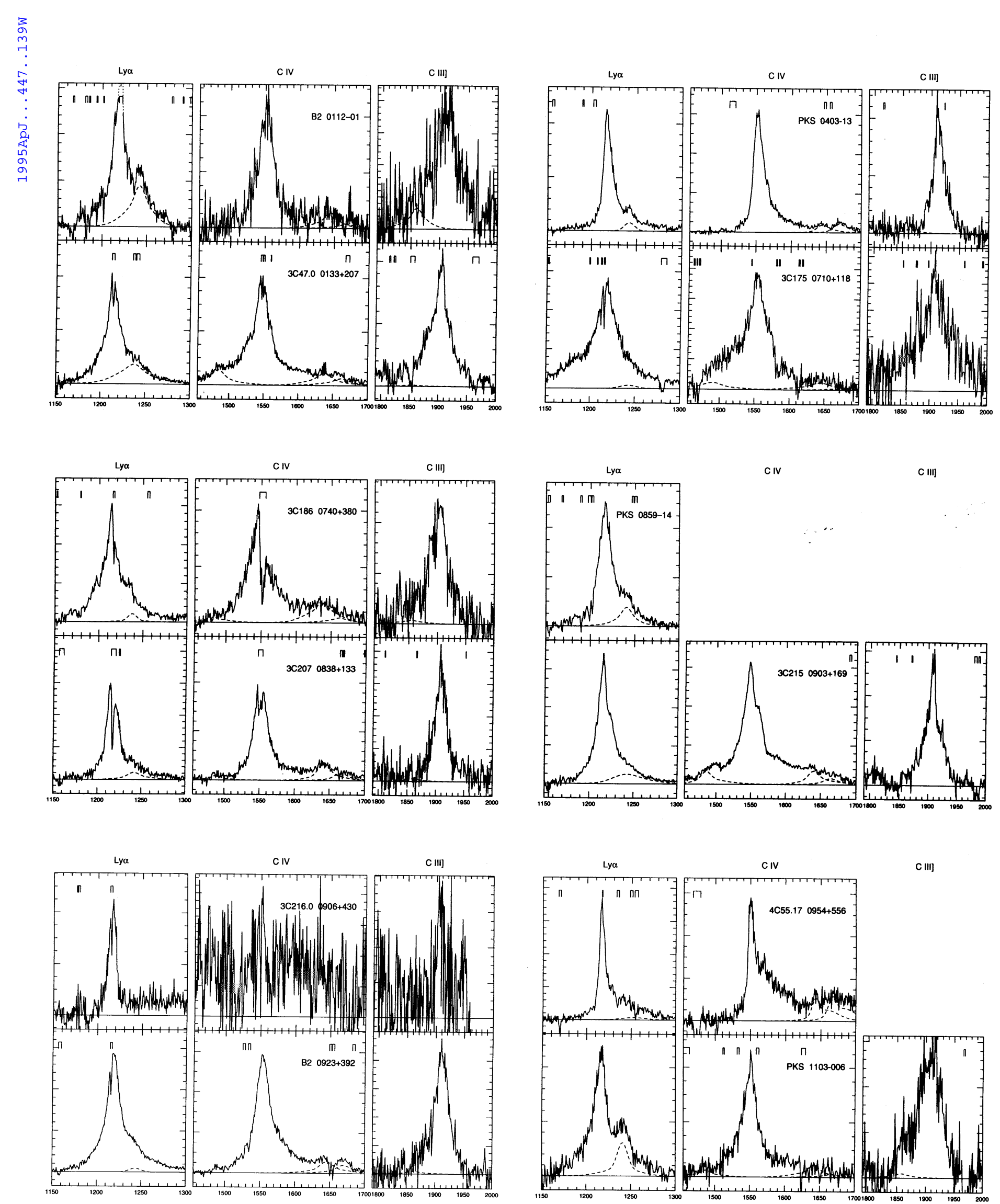

Fig. 3.-Details of the continuum-subtracted profiles for strong emission lines. Dashed profiles are fits to weaker blends that have been subtracted from the data before measuring the strong emission line parameters (see $\S 5.1$ ). The ordinate is $F_{\lambda}$. Rest wavelengths are shown, and the abscissa scale of the plots is such that profiles can be compared directly in velocity. Galactic, intervening intergalactic, and associated absorption systems are indicated. 

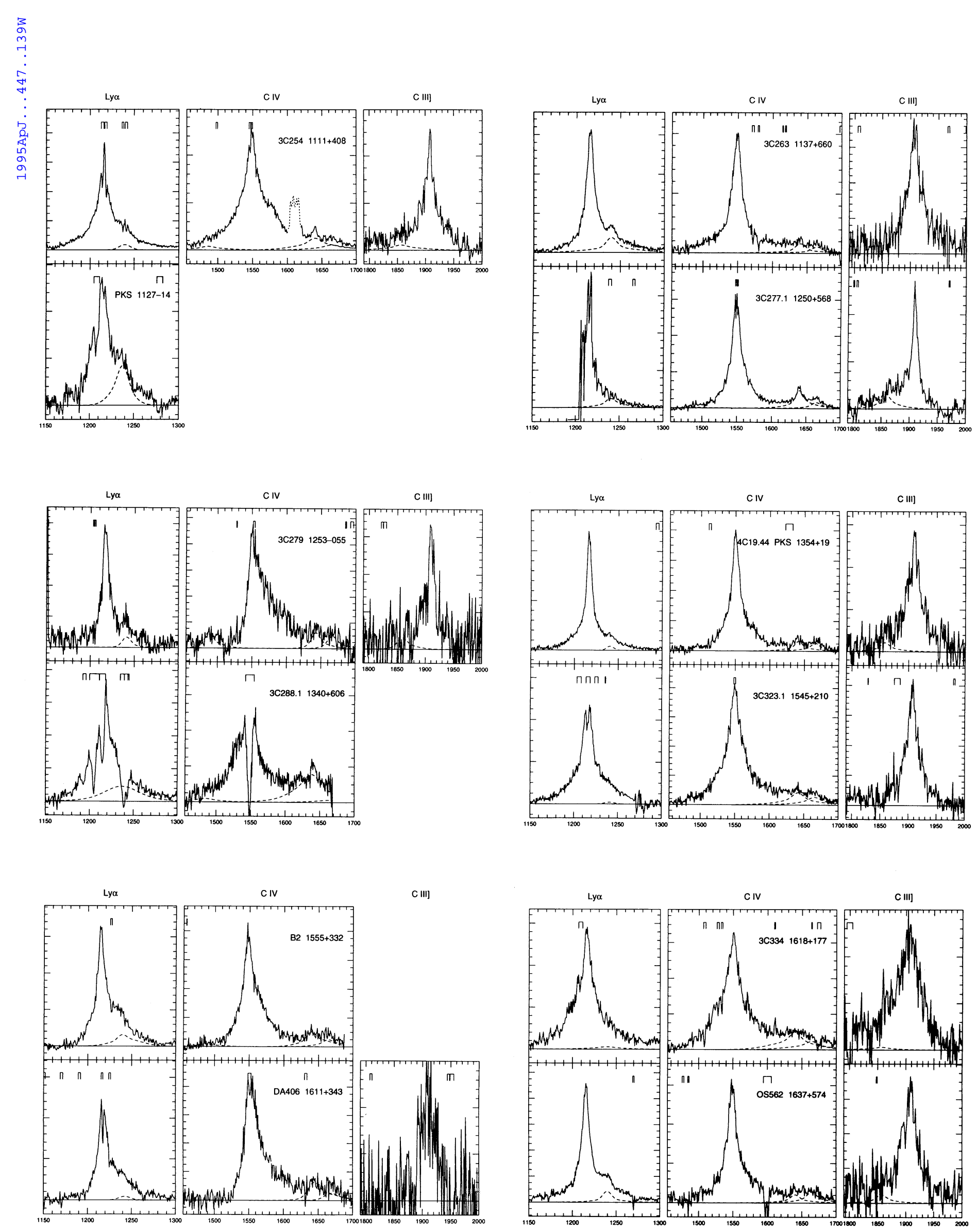

Fig. 3.-Continued 

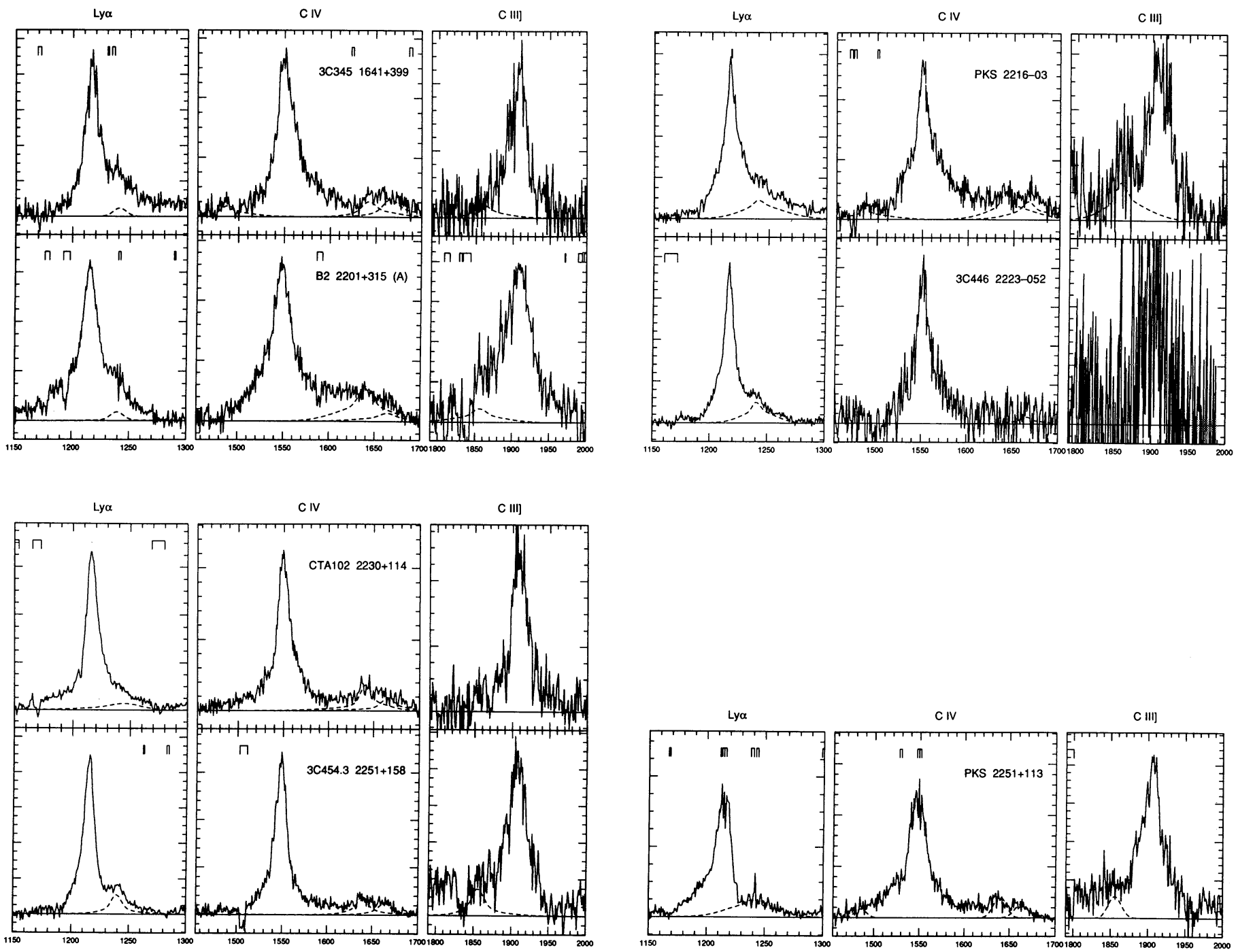

Fig. 3.-Continued

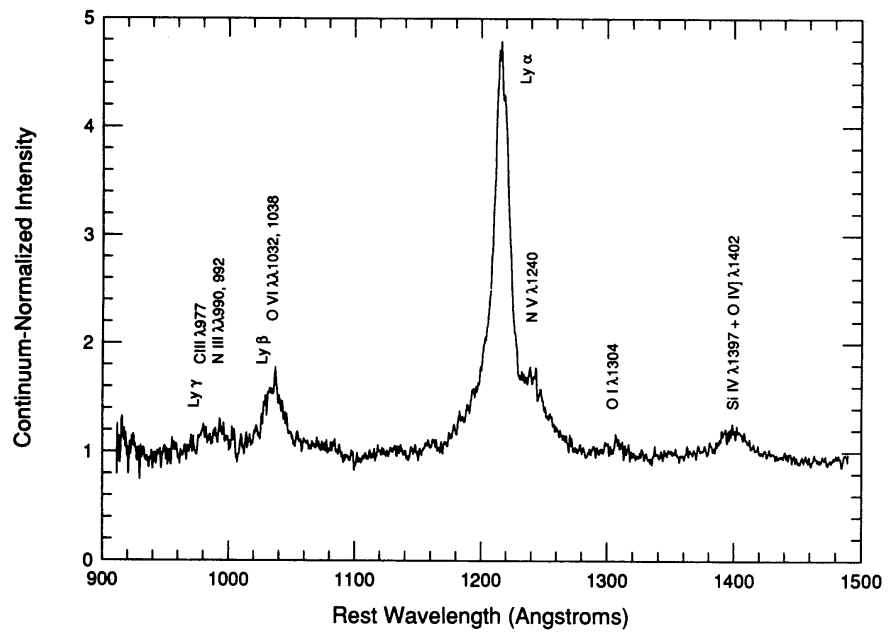

Fig. 4.-Spectral region from rest wavelengths 912 to $1500 \AA$ derived from a composite of the spectra of B2 $2201+31$ A, PKS $2251+11$, OS 562, and $3 C$ 454.3. It shows the expected wavelengths of weaker features below $1216 \AA$ : Ly $\gamma, C$ III $\lambda 977, \mathrm{~N}$ III $\lambda \lambda 990,992, \operatorname{Ly} \beta$, and O VI $\lambda \lambda 1032,1038$.
N v $\lambda 1240$ emission, etc.) are collisionally suppressed (Rees, Netzer, \& Ferland 1989).

We have co-added four of the best spectra that extend to about $912 \AA$ rest wavelength, and the result is shown in Figure 4 , where the rest wavelength scale is defined by the peak of the C IV $\lambda 1549$ line, assumed to be at $1549.0 \AA$ rest wavelength. The strong feature measured at $1035.6 \AA$ is clearly dominated by $O$ vi $\lambda 1034$, while $\operatorname{Ly} \beta$ is a very minor contributor with an upper limit of less than $15 \%$ of the $\lambda 1035$ feature in all except the noisiest spectra. The high-ionization $O$ vI line in the composite, or in individual quasar spectra, does not appear to be strongly blueshifted as is observed for some QSOs in some other high-ionization lines (e.g., Espey et al. 1989). The next strongest feature peaks near $990 \AA$, suggesting that N III $\lambda 991$ dominates at this wavelength. In the composite, this feature is asymmetric with a stronger short-wavelength wing. This is probably C III $\lambda 977$ emission which, in some spectra, can be stronger than $\mathrm{N}$ III 2991 . Typical line intensities, normalized to 100 for $\mathrm{Ly} \alpha$, are C III $\lambda 977, \mathrm{~N}$ III $\lambda 991, \mathrm{O}$ vi $\lambda 1034, \mathrm{~N}$ v $\lambda 1240$, $\mathrm{C}$ IV $\lambda 1549, \mathrm{C}$ III] $\lambda 1909=5,4,23,14,56,15$, although the intrinsic dispersion is large. There is often clear, excess emission near $1080 \AA$ and between $1100 \AA$ and Ly $\alpha$ (Fig. 4). 
Our measurements of the O vi $\lambda 1034 / \mathrm{Ly} \alpha$ ratio cover the range $0.1-0.4$, with a mean of $\sim 0.21$. The ratio $(\mathrm{O}$ VI $\lambda 1034+\operatorname{Ly} \beta) /(\operatorname{Ly} \alpha+N v \lambda 1240)$ measured in lower resolution IUE spectra of similar low-redshift quasars by Kinney et al. $(1985,1987)$ is in good agreement with our measurements, including agreement within \pm 0.02 for the ratios of the three objects in common (see also Laor et al. 1994). The only careful measurements for high-redshift quasars that we could find, removing obvious $\mathrm{Ly} \alpha$ forest absorption, were by Wilkes (1984): 0.18 and 0.09 . We have attempted the same measurements using the high-redshift, high-resolution data of Sargent, Steidel, \& Boksenberg (1989) and Sargent, Boksenberg, \& Steidel (1988) and find values consistent, on average, with all the above values: there is no evidence yet for a difference between high- and low-redshift quasars. Our new data for the $O$ vi $\lambda 1034 /$ Ly $\alpha$ line ratio confirms the suggestion (e.g., Ferland $\&$ Persson 1989) that high-ionization material and a small BLR is required in order to explain the emission-line spectrum.

The C III $\lambda 977$ line is very weak or undetectable in a wealth of $H S T$ archival spectra (e.g., Bahcall et al. 1993). Ours are perhaps better than previous data in this region (e.g., Laor et al. 1994, 1995). Still, we find it to be quite weak, with mean ratio $\mathrm{C}$ III $\lambda 977 / \mathrm{Ly} \alpha \sim 0.05$, suggesting models with density $\lesssim 10^{10-11} \mathrm{~cm}^{-3}$ (Rees et al. 1989). Note that these densities are an average over the entire BLR, and the weak C III $\lambda$ line intensity does not exclude a small region with a much higher density.

We have detected the $\mathrm{N}$ III $\lambda 991$ line in a few objects, with up to $\sim 5 \%$ of the $\mathrm{Ly} \alpha$ intensity. Given the intrinsic dispersion, this is consistent with results by Laor et al.(1994, 1995).

The continua and line profiles show some striking trends.

The spectra shown in Figures $2 a-2 d$ are ordered by continuum spectral index, $\alpha_{\mathrm{Uv}}$. Plotted as $\log F_{\lambda}$ versus $\log \lambda$, they appear increasingly flat; on a presentation more conventional for spectral energy distributions, they are increasingly steep: $F_{v} \propto v^{-\alpha \mathrm{Uv}}$, with $\alpha_{\mathrm{UV}}$ increasing from about 0.5 to 1.9 . We note the striking but not surprising trend - the high $\alpha_{U V}$ spectra of Figures $2 c$ and $2 d$ are all of time-variable, core-dominant quasars (Fig. 5). Lobe-dominant sources are present only in Figures $2 a$ and $2 b$. Although there are some core-dominant quasars in Figures $2 a$ and $2 b$ we note that these sources are either variable but not especially bright at the time of our observations or they are core-dominant but belong to the class of steep radio spectrum core-dominant sources. We also note a significant decrease in emission-line EW with increasing core dominance. This, and the steep ultraviolet spectrum, is at least

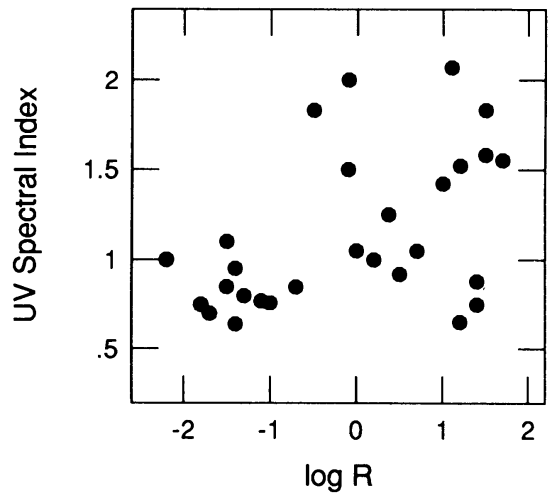

Fig. 5.-The ultraviolet spectral index, $\alpha_{\mathrm{Uv}}\left(F_{v} \propto v^{-\alpha_{\mathrm{Uv}}}\right)$ as a function of radio core dominance, $\log R$. partly the result of a significant contribution from a synchrotron component (Wills 1991; Wills et al. 1995).

We also note a tendency for the broad C IV $\lambda 1549$ lines of core-dominant objects to show strong red wings; see, in particular, 3C 279 (see also Netzer et al. 1994) and 4C 55.17. None shows stronger blue wings. Lobe-dominant quasars show more symmetric profiles. These profiles contrast sharply with the strong blue wing asymmetry of radio-quiet QSOs (Fig. 6). There is almost no overlap in Asym (at $20 \%$ or $25 \%$ of peak line intensity) between core-dominant and radio-quiet QSOs, and the differences between core-dominant or all radio-loud quasars and radio-quiet QSOs are highly significant (using the Wilcoxon summed rank test). The "radio-quiet" sample used is described by Wills et al. 1993b; not all are confirmed radioquiet, so the two with stronger red wings may later turn out to be radio-loud. This difference does not appear to depend on optical luminosity, as radio-quiet QSOs from the $H S T$ archives matched to the luminosity of our radio-loud sample show the same effect. Profile differences between the core- and lobe-dominant sources, or between lobe-dominant and radioquiet QSOs, are less significant but still present at the $\sim 3 \sigma$ level. The reasons for the differences may lie in the gas kinematics, or in the strength of the $\lambda 1600$ feature that is probably dominated by $\mathrm{Fe}$ II emission. Both may play a part.

Another interesting correlation with $\log R$ (which is probably a measure of orientation of the central engine) is a signifi-

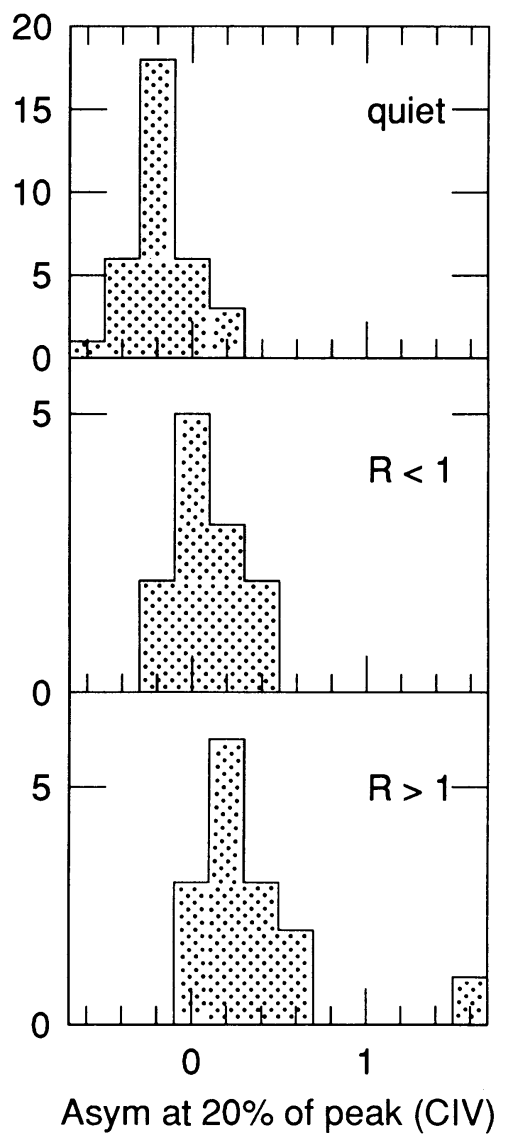

FIG. 6.-Histograms showing the significant differences in distributions of the asymmetry index for radio-quiet QSOs, core-dominant quasars $(R>1)$, and lobe-dominant quasars $(R<1)$. 


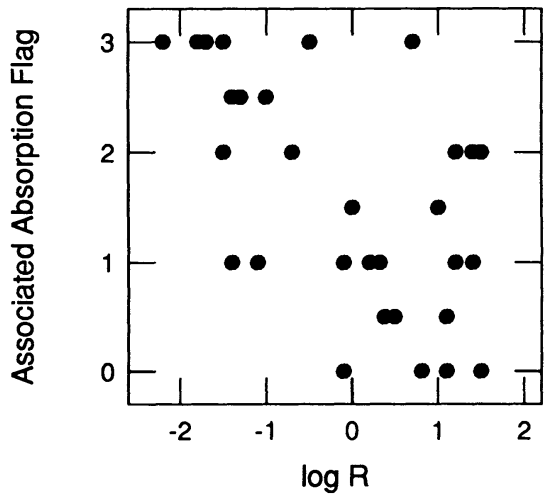

Fig. 7.-The strength of associated absorption as a function of radio core dominance, $\log R$. Strength flag $=0$ means no absorption was detected, and flag $=3$ means the strongest absorption. The flags for Ly $\alpha$ and $C$ Iv have been averaged.

cant increase in strong associated absorption with decreasing $\log R$-as if the absorption probability increases toward smaller "disk" latitudes (Student's $t=3.7 \sigma ;$ Fig. 7). This does not appear to be a result of associated absorption being easier to see in broader lines, as that correlation (absorption flag vs. FW50M) is much weaker (Student's $t=2.2 \sigma$ ). This relation ties in with the idea that associated absorption may be occurring in high-ionization material evaporated from a dusty torus (Voit, Weymann, \& Korista 1993).

These trends will be discussed in more detail when we present the extension of these spectra to longer wavelengths.

Anne Kinney, George Hartig, Anuradha Koratka, Daniel Golombek, Tony Keyes, Jen Christiansen, and their colleagues at STScI suffered innumerable questions, and their patience is much appreciated. We also thank Buell Januzzi, Ari Laor, Barbara McArthur, and John Bahcall for help, advice and for supplying data before publication. We are very grateful to the Space Telescope Science Institute (STScI) for support under grant number HST GO-2578.01-87A RQ-Q. STScI is operated by AURA, Inc., under NASA contract NAS5-26555. We also thank the US-Israel Binational Science Foundation for support (BSF 8900179).

\section{REFERENCES}

Anderson, S. F. 1992, Faint Object Spectrograph Science Verification Report CAL/FOS-075 (Baltimore: STScI)

Ayres, T. R. 1993, Faint Object Spectrograph Science Verification Report CAL/FOS-115 (Baltimore: STSCI)

Bahcall, J. N., et al. 1993, ApJS, 87, 1

Baldwin. J. A.. Ferland, G. J., Carswell, R. F., Phillips, M. M., Wilkes, B., \& Williams, R. E. 1993, in preparation

Bohlin, R. C. 1993, Faint Object Spectrograph Science Verification Report CAL/FOS-097 (Baltimore: STScI)

Bohlin, R. C., \& Cox, C. 1992, HST Calibration Status Report (Baltimore: STScI)

Bohlin, R. C., \& Neill, J. D. 1992, HST FOS Instrument Science Report No. 84 (Baltimore: STScI)

Brotherton, M. S., Wills, B. J., Francis, P. J., \& Steidel, C. C. 1994, ApJ, 423, 131

Burstein, D., \& Heiles, C. 1982, AJ, 87, 1165

Cardelli, J. A., Clayton, G. C., \& Mathis, J. S. 1989, ApJ, 345, 245

Espey, B. R., Carswell, R. F., Bailey, J. A., Smith, M. G., \& Ward, M. J. 1989, ApJ, 342, 666

Evans, I. N. 1993, Faint Object Spectrograph Science Verification Report CAL/FOS-107 (Baltimore: STScI)

Ferland, G. J., \& Persson, S. E. 1989, ApJ, 347, 656

Ford, H. C., \& Hartig, G. F. 1990, Faint Object Spectrograph Handbook, version 1.1 (Baltimore: STSCI)

Francis, P. J., Hewett, P. C., Foltz, C. B., \& Chaffee, F. H. 1992, ApJ, 398, 476

Hamann, F., \& Ferland, G. J. 1993, ApJ, 418, 11

Jannuzi, B. T., \& Hartig, G. F. 1994, in Proc. HST Calibration Workshop, ed. J. C. Blades (Baltimore: STScI), 215

Junkkarinen, V., et al. 1992, Faint Object Spectrograph Science Verification Rept. CAL/FOS-066 (Baltimore: STScI)

Keyes, C. D. 1994, in Proc. HST Calibration Workshop, ed. J. C. Blades (Baltimore: STScI), 138 \& 209

Kinney, A. L. 1992, Faint Object Spectrograph Handbook, Version 2.0 (Baltimore: STScI)

Kinney, A. L., \& Bohlin, R. C. 1993, Faint Object Spectrograph Science Verification Rept. CAL/FOS-103 (Baltimore: STScI)

Kinney, A. L., Huggins, P. J., Bregman, J. N., \& Glassgold, A. E. 1985, ApJ, 291,128

Kinney, A. L., Huggins, P. J., Glassgold, A. E., \& Bregman, J. N. 1987, ApJ, 314,145

Kondo, Y. 1987, in Exploring the Universe with the IUE Satellite, ed. Y. Kondo, W. Wamsteker, A. Boggess, M. Grewing, C. de Jager, A. L. Lane, J. L. Linsky, \& R. Wilson (Dordrecht: Reidel), 1

Koratkar, A. 1994, FOS Calibration Manual (Baltimore: STScI)

Koratkar, A., \& Taylor, C. J. 1993, Faint Object Spectrograph Science Verification Rept. CAL/FOS-096 (Baltimore: STScI)
Kriss, G. A., et al. 1992, ApJ, 392, 485

Kriss, G. A., Blair, W. P., \& Davidsen, A. F. 1992, Faint Object Spectrograph Science Verification Report CAL/FOS-070 (Baltimore: STScI)

Laor, A., Bahcall, J. N., Jannuzi, B. T., Schneider, D. P., \& Green, R. F. 1995 , ApJ, in press

Laor, A., Bahcall, J. N., Jannuzi, B. T., Schneider, D. P., Green, R. F., \& Hartig, G. F. 1994, ApJ, 420, 110

Lasker, B. M. 1990, AJ, 99, 2019

Lindler, D. J., \& Bohlin, R. C. 1993, Faint Object Spectrograph Science Verification Report CAL/FOS-102 (Baltimore: STSCI)

Lyons, R., Baity, W. A., Beaver, E. A., Cohen, R. D., Junkkarinen, V. T., \& Linsky, J. B. 1992a, Faint Object Spectrograph Science Verification Report CAL/FOS-083 (Baltimore: STScI)

Lyons, R., Linsky, J. B., Beaver, E. A., Baity, W. A., \& Rosenblatt, E. I. 1992b, Faint Object Spectrograph Science Verification Report CAL/FOS-080 (Baltimore: STScI)

Neill, J. D., Bohlin, R. C., \& Hartig, G. 1992, Faint Object Spectrograph Science Verification Report CAL/FOS-077 (Baltimore: STScI)

Netzer, H. 1985 ApJ, 289, 451

Netzer, H., \& Wills, B. J. 1983, ApJ, 275, 445

Netzer, H., Kazanas, D., Wills, B. J., Wills, D., Baldwin, J. A., Ferland, G. J.,

Han, M., Brotherton, M. S., \& Browne, I. W. A. 1994, ApJ, 430, 191

Rees, M. J., Netzer, H., \& Ferland, G. J. 1989, ApJ, 347, 640

Rosa M. R. 1993, Faint Object Spectrograph Science Verification Report CAL/FOS-114 (Baltimore: STScI)

Sargent, W. L. W., Boksenberg, A., \& Steidel, C. C. 1988, ApJS, 68, 539

Sargent, W. L. W., Steidel, C. C., \& Boksenberg, A. 1989, ApJS, 69, 703

Taylor, C. J., \& Keyes, C. D. 1993, Faint Object Spectrograph Science Verification Report CAL/FOS-000 (Baltimore: STScI)

Véron-Cetty, M.-P., \& Véron, P. 1991, A Catalogue of Quasars and Active Nuclei, ESO Scientific Report No. 10 (5th ed.; Munich: ESO)

Voit, G. M., Weymann, R. J., \& Korista, K. T. 1993, ApJ, 413, 95

Wilkes, B. J. 1984, MNRAS, 207, 73

Wills, B. J. 1991, in Variability of AGN, ed. H. R. Miller \& P. J. Wiita (Cambridge: Cambridge Univ. Press), 87

Wills, B. J., \& Browne, I. W. A. 1986, ApJ, 302, 56

Wills, B. J., Brotherton, M. S., Fang, D., Steidel, C. C., \& Sargent, W. L. W. 1993b, ApJ, 415, 563

Wills, B. J., Hough, J. H., Bailey, J. A., \& Wills, D. 1995, in preparation

Wills, B. J., Netzer, H., Brotherton, M. S., Han, M., Wills, D., Baldwin, J. A. Ferland, G. J., \& Browne, I. W. A. 1993a, ApJ, 410, 534

Wills, B. J., Netzer, H., \& Wills, D. 1980, ApJ, 242, L1

1985, ApJ, 288, 94

Wills, B. J., Wills, D., Breger, M., Antonucci, R. R. J., \& Barvainis, R. 1992, ApJ, 398, 454 